\title{
Accurate spatiotemporal predictions of daily stream temperature from statistical models accounting for interactions between climate and landscape
}

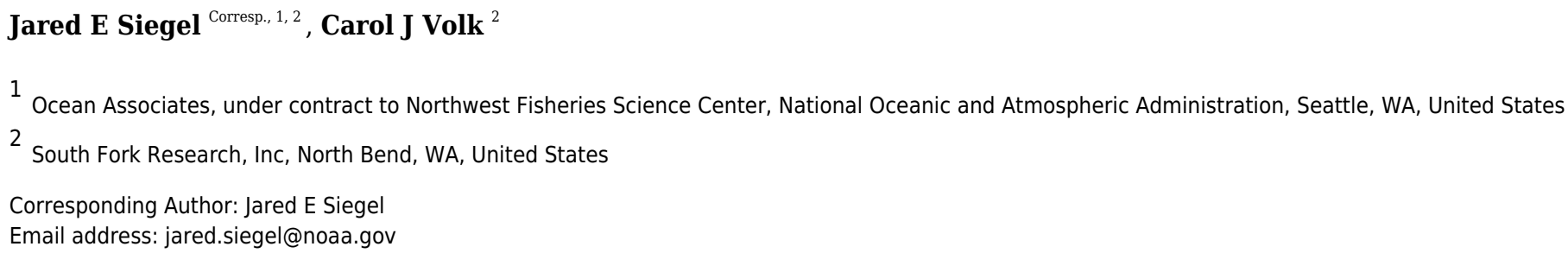

Spatial and temporal patterns in stream temperature are primary factors determining species composition, diversity and productivity in stream ecosystems. The availability of spatially and temporally continuous estimates of stream temperature would improve the ability of biologists to fully explore the effects of stream temperature on biota. Most statistical stream temperature modeling techniques are limited in their ability to account for the influence of variables changing across spatial and temporal gradients. We identified and described important interactions between climate and spatial variables that approximate mechanistic controls on spatiotemporal patterns in stream temperature. With identified relationships we formed models to generate reach-scale basin-wide spatially and temporally continuous predictions of daily mean stream temperature in four Columbia River tributaries watersheds of the Pacific Northwest, USA. Models were validated with a testing dataset composed of completely distinct sites and measurements from different years. While some patterns in residuals remained, testing dataset predictions of selected models demonstrated high accuracy and precision (averaged RMSE for each watershed ranged from $0.85-1.54{ }^{\circ} \mathrm{C}$ ) and was only $17 \%$ higher on average than training dataset prediction error. Aggregating daily predictions to monthly predictions of mean stream temperature reduced prediction error by an average of $23 \%$. The accuracy of predictions was largely consistent across diverse climate years, demonstrating the ability of the models to capture the influences of interannual climatic variability and extend predictions to timeframes with limited temperature logger data. Results suggest that the inclusion of a range of interactions between spatial and climatic variables can approximate dynamic mechanistic controls on stream temperatures. 


\section{Accurate spatiotemporal predictions of daily stream}

2 temperature from statistical models accounting for

3 interactions between climate and landscape

4

5

6

7

Jared E. Siegel ${ }^{1,2 *}$, Carol J. Volk ${ }^{1}$

${ }^{1}$ South Fork Research, Inc., North Bend, WA, U.S.A

${ }^{2}$ Ocean Associates, Inc. contracted to the Northwest Fisheries Science Center, National Marine Fisheries Service, National Oceanic and Atmospheric Administration, Seattle, WA, U.S.A

${ }^{*}$ Current affiliation

Corresponding Author:

Jared E. Siegel

2725 Montlake Boulevard East

Seattle, WA 98112

Email address: jared.siegel@noaa.gov

\section{Abstract}

Spatial and temporal patterns in stream temperature are primary factors determining species composition, diversity and productivity in stream ecosystems. The availability of spatially and temporally continuous estimates of stream temperature would improve the ability of biologists to fully explore the effects of stream temperature on biota. Most statistical stream temperature modeling techniques are limited in their ability to account for the influence of variables changing across spatial and temporal gradients. We identified and described important interactions between climate and spatial variables that approximate mechanistic controls on spatiotemporal patterns in stream temperature. With identified relationships we formed models to generate reachscale basin-wide spatially and temporally continuous predictions of daily mean stream temperature in four Columbia River tributaries watersheds of the Pacific Northwest, USA. Models were validated with a testing dataset composed of completely distinct sites and measurements from different years. While some patterns in residuals remained, testing dataset predictions of selected models demonstrated high accuracy and precision (averaged RMSE for each watershed ranged from $0.85-1.54{ }^{\circ} \mathrm{C}$ ) and was only $17 \%$ higher on average than training dataset prediction error. Aggregating daily predictions to monthly predictions of mean stream temperature reduced prediction error by an average of $23 \%$. The accuracy of predictions was largely consistent across diverse climate years, demonstrating the ability of the models to capture the influences of interannual climatic variability and extend predictions to timeframes with limited temperature logger data. Results suggest that the inclusion of a range of interactions 
40

41

42

43

44

45

46

47

48

49

50

51

52

53

54

55

56

57

58

59

60

61

62

63

64

65

66

67

68

69

70

71

72

73

74

75

76

77

78

79

between spatial and climatic variables can approximate dynamic mechanistic controls on stream temperatures.

\section{Introduction}

Spatial and temporal patterns in stream temperature are primary factors determining species composition, diversity, and productivity in stream ecosystems (Vannote et al. 1980). Ichthyofauna and most other stream dwelling species are ectotherms, thus temperature dictates the rates of metabolic and physiological processes influencing growth, development, and the timing of life history events. Stream temperature also impacts biota by affecting the dissolved oxygen content of water and biogeochemical processes such as nutrient cycling, decomposition rates, and eutrophication. Many human activities, such as deforestation (Holtby 1988) and flow regulation by dams and diversions (Sinokrot and Gulliver 2014), have major effects on

stream temperature. Additionally, climate change has already caused increases in stream temperature (Isaak et al. 2010, 2012, Kaushal et al. 2010, Ruesch et al. 2012) and changes in the timing and magnitude of discharge (Luce and Holden 2009, Riedel and Larrabee 2016), with effects on the productivity and spatial distributions of resident species (Lawrence et al. 2014). Due to the ecological importance of stream temperature combined with the potential impact of human activities, there is substantial interest among water and fisheries managers to improve our understanding of stream temperature patterns and influences.

Investigations into the effects of stream temperature on biota are best supported by temperature metrics at spatial and temporal grains relatable to the biological responses of interest. For example, in Pacific salmon stream temperature has been shown to affect numerous life history events; including the timing and success of the spawning migration (Crozier et al. 2011), pre-spawn mortality rates (Bowerman et al. 2017), egg incubation times and larval survival (Pankhurst and Munday 2011), the size and timing of emergence (Beacham and Murray 1990), juvenile energetic demands and growth rates (Crozier et al. 2010), and the size and timing of smolting (Sykes and Shrimpton 2010). Each of these life history events occurs at temporally distinct time periods and in spatially distinct habitats. Accordingly, a comprehensive examination of the effects of stream temperatures on Pacific salmon would benefit from spatially and temporally continuous estimates of stream temperature within the watershed they inhabit allowing for a full exploration of temperature effects and the summarization of temperature predictions into specific metrics of interest.

Most stream temperature data are collected by loggers which capture instantaneous point measurements at pre-determined temporal intervals. Modeling techniques are then utilized to expand the utility of logger data by making hindcast/forecast predictions across space or time and to describe influences on stream temperature from climate/spatial variables (e.g., McNyset et al. 2015, Segura et al. 
80

81

82

83

84

85

86

87

88

89

90

91

92

93

94

95

96

97

98

99

100

101

102

103

104

105

106

107

108

109

110

111

112

113

114

115

116

117

118

119

2015, Letcher et al. 2016, Turschwell et al. 2016, Isaak et al. 2017). Water temperature models are generally classified as either deterministic or stochastic/statistical (Caissie 2006, Benyahya et al. 2007). Deterministic models are based on mathematical representation of the underlying physics of heat exchange between the river and the surrounding environment (e.g., Caissie et al. 2007). In contrast, most statistical models utilize air temperature (e.g., Mohseni et al. 1998, Pilgrim and Fang 1998) as a surrogate for net heat exchange processes in the absence of detailed information on heat fluxes, as both are dependent on solar radiation (Webb et al. 2008). Consequently, statistical models require less site-specific data and are generally easier to scale than deterministic models (Benyahya et al. 2007).

To produce accurate predictions across temporal (diel, daily, seasonal, and annual) and spatial (microhabitat, reach, tributary, and watershed) gradients, a statistical model needs to parameterize relationships that approximate the complex interactions between geography and climate that determine stream temperature. Climatic factors, such as air temperature, snowpack melt, and stream discharge levels affect heat exchange within streams, driving seasonal and interannual variability in temperature (Caissie 2006). The spatial characteristics of streams leads to heterogeneity in the localized responses to climate within and across watersheds. For example, higher gradient watersheds (Mayer 2012) and more shaded stream reaches (Holtby 1988, Johnson 2004) tend to be cooler in the summer and higher elevation watersheds as well as groundwater and snowmelt dependent streams are less sensitive to air temperature changes (Luce et al. 2014, Lisi et al. 2015, Isaak et al. 2016, Winfree et al. 2018). Similarly, hyporheic exchange (Arrigoni et al. 2008) and tributary confluences (Ebersole et al. 2003) can lead to localized zones with distinct temperature patterns. The resulting complexity in spatiotemporal patterns in stream temperature can lead to streams with diverse thermal profiles in similar climatic regions (Fullerton et al. 2015).

However, most statistical stream temperature modeling techniques are limited in their ability to account for the influence of variables changing across spatial and temporal gradients, which restricts the universality of derived relationships. Consequently, many statistical modeling approaches reduce the spatial or temporal component of monitoring data, greatly limiting their utility. For example, while the majority of statistical models depend on the air temperature/stream temperature relationship, this relationship varies spatially within basins (Pilgrim and Fang 1998, Mayer 2012, Steel et al. 2016) and across basins (Arismendi et al. 2013, Luce et al. 2014, Mauger et al. 2017, Winfree et al. 2018) as a consequence of distinct landcover and geomorphological influences. Accordingly, air temperature driven models are often fit to single sites as the validity of derived relationships may be spatially limited. The relationship between air and water temperature is not consistent over years (Arismendi et al. 2014) and seasons (Lisi et al. 2015) due to climatic effects, such as variability in 
120

121

122

123

124

125

126

127

128

129

130

131

132

133

134

135

136

137

138

139

140

141

142

143

144

145

146

147

148

149

150

151

152

153

154

155

156

157

158

159

discharge levels and the influence of snowpack. While a few recent statistical modeling studies have attempted to account for variation in the nature of the relationship with air temperature in diverse ways (e.g., Li et al. 2014, Segura et al. 2015, Jackson et al. 2018), modeling efforts could benefit from further exploration and discussion of effective methodologies.

Spatial modeling techniques, which utilize statistical auto-correlation to describe how upstream sites influence downstream sites, have recently become popular to predict stream temperature across entire watersheds (e.g., Peterson et al. 2013, Isaak et al. 2014, Jackson et al. 2017). Most spatial modeling techniques require dense monitoring networks (Marsha et al. 2018) and, with a few exceptions (e.g., Jackson et al. 2018, Hocking et al. 2018), primarily been used to predict temporally summarized metrics, such as the mean August max weekly temperature (Isaak et al. 2017) or the maximum weekly mean stream temperature (Ruesch et al. 2012), as opposed to continuous estimates of temperature. This is likely a consequence of spatial correlations and covariate relationships changing with climatic variability (Steel et al. 2016, Jackson et al. 2018). For example, stream temperatures are likely to be more correlated across space during periods of high flows due to shorter water residency times and increased thermal inertia limiting the effect of air temperature and other influences. Consequently, models that depend on such autocorrelation techniques or other hierarchical methods may see large declines in precision when predicting into new temporal or physical spaces which are uninformed by such methods (e.g., Hocking et al. 2018).

Despite clear theoretical evidence for the influence of covariates on stream temperature being conditional on other climatic and spatial influences, few statistical modeling studies have attempted to extensively utilize interactions to approximate such physical mechanism (e.g., Hocking et al. 2018, Jackson et al. 2018), and the utility of many interactions remains largely unexplored. Our objective was to identify and describe important interactions between climate and spatial variables and to utilize these relationships to model reach-scale spatially and temporally continuous patterns in daily mean stream temperature across complex watersheds. The justification for this investigation is based on three assertions: 1) the shifting influence of the effects of variables with climate and space can be approximated by including interaction terms based on mechanistic principles, 2) accounting for this variability in stream temperature with variable relationships, as opposed to statistical methods, can inform mechanisms and allowing for the expansion of predictions across space and time, and 3) few studies have extensively explored the utility of utilizing interactions to model stream temperature and thus there is potential for substantial improvement.

To achieve our objective, we compared two statistical modeling techniques, simple linear models and general additive models (GAMs), fit to daily mean temperature data throughout the entire year using a suite of climatic and spatial variables. GAM 
160 models can easily account for non-linear relationships, such as between stream

161

162

163

164

165

166

167

168

169

170

171

172

173

174

175

176

177

178

179

180

181

182

183

184

185

186

187

188

189

190

191

192

193

194

195

196

197

198

199

temperature and air temperature, with non-parametric smoothers (Wood 2006). However, the benefits of their flexibility are balanced by their tendency to overfit data. Separate models of both types were generated for four Columbia River tributary basins in the Pacific Northwest (United States) with substantial interest in stream temperature due to the presence of federally listed populations of endangered Chinook salmon (Oncorhynchus tshawytscha) or steelhead (Oncorhynchus mykiss), which have thermally sensitive life histories. We explored whether spatiotemporal variability could be accounted for using only variables and interactions rather than utilizing hierarchical or autocorrelation statistical modeling techniques. Modeled relationships were validated by predicting testing datasets composed of years and logger sites completely distinct from the model training datasets.

\section{Materials \& Methods}

\section{Study watersheds}

We modeled stream temperature in four tributary watersheds of the Columbia River located in the northwestern United States, the Wenatchee River, the Chiwawa River, the Middle Fork John Day River (M.F. John Day), and the Tucannon River (Figure 1). These watersheds were selected to represent a range in size (474 to 3,452 $\mathrm{km} 2$ ), wetness (mean annual discharge of 5 to $91 \mathrm{~m} 3 / \mathrm{s}$ ) and climatic regimes for exploring relationships among physical and climatic variables. All four study watersheds are influenced by winter snowpack and seasonal climate patterns, leading to high spring flows during the snowmelt and low flows during the late summer/early fall dry period.

Wenatchee River. The Wenatchee River drains the east side of the Cascade Mountains (Washington, USA) and flows southwest to the Columbia River. It is the largest of the study watersheds, with an area of $3,452 \mathrm{~km} 2$ and mean discharge of 91 $\mathrm{m} 3 / \mathrm{s}$. The upper reaches are characterized by high alpine mountains and national forest lands while the lower reaches support significant agricultural production (e.g. apples and cherries). Small high elevation cirque glaciers influence some of the tributaries and are most prominent in the White River. Lake Wenatchee $(10.0 \mathrm{~km} 2)$, located at the confluence of the White and Little Wenatchee tributaries, is a prominent feature in the central watershed.

Chiwawa River: The Chiwawa River is a tributary of the upper Wenatchee River, with its confluence just below Lake Wenatchee. We included analysis of the Chiwawa River separately as a test of how scale affects model accuracy within the same geographical region. The river drains high-mountain and forest lands, representing about $14 \%$ of the

Peer) reviewing PDF | (2019:03:36199:1:1:NEW 2 Aug 2019) 
200

201

202

203

204

205

206

207

208

209

210

211

212

213

214

215

216

217

218

219

220

221

222

223

224

225

226

227

228

229

230

231

232

233

234

235

236

237

238

239

drainage area of the Wenatchee watershed and $16 \%$ of the mean annual discharge (area $474 \mathrm{~km} 2$, mean discharge $14 \mathrm{~m} 3 / \mathrm{s}$ ).

Middle Fork John Day River: The M.F. John Day is a tributary of the upper John Day draining the dry pine forests of the Blue Mountains in eastern Oregon. With an area of $2,088 \mathrm{~km} 2$, the basin is about $60 \%$ the size of the Wenatchee River but is significantly drier with very low summer flows (mean discharge $7.28 \mathrm{~m} 3 / \mathrm{s}$ ). The watershed contains habitats ranging from near-alpine to sagebrush steppe in the lower reaches near its confluence with the North Fork John Day River. Due to low coverage of sites in the lower basin, we only modeled the watershed at the confluence with Slide Creek and above (Figure 1, modeled area 1,178 km2).

Tucannon River: The Tucannon is a tributary of the Snake River draining the Blue Mountains in the southwest corner of Washington State. The upper basin is

characterized by mountainous pine forests, while the lower watershed contains dry sage bush and agricultural lands. The Tucannon is a relatively dry system and is similar to the M.F. John Day in both discharge and size (area 1,300 km2, mean discharge 4.81 $\mathrm{m} 3 / \mathrm{s}$ ). With relatively few temperature monitoring locations on tributaries, we restricted the analysis to the mainstem Tucannon from the confluence with the Snake to the headwaters in the Blue Mountains.

\section{Stream temperature data}

For each watershed, all available stream temperature data from two regional databases were downloaded and utilized for model training and testing respectively (Figure 2). Stream temperature data sourced from the Columbia Habitat Monitoring Program (ISEMP/CHaMP 2017) was downloaded for all study watersheds for years 2012-2017 and used as the model training datasets. Additional stream temperature data for the Wenatchee training dataset was provided by the Washington Department of Fish and Wildlife (Jeremy Cram, personal communication). Model testing data for these watersheds, collected from loggers at distinct sites and during different years, was downloaded from the NorWest Regional Stream Temperature Database (Isaak et al. 2017, https://www.fs.fed.us/rm/boise/AWAE/projects/NorWeST.html). Testing data was collected on the Wenatchee and Chiwawa from 2003-2011,1997-2011 for the M.F. John Day, and 2001-2011 for the Tucannon. Both testing and training datasets contained years with diverse climate conditions (Figures S1-3). Although potential distinctions in collection procedures between the datasets could cause discrepancies, combining datasets gave us the longest possible time series to examine the ability of models to account for interannual variability. While training and testing datasets were controlled for quality by their respective publishers before downloading, we visually examined all data for anomalies before utilization in this study leading to the removal of a minimal 
240 amount of data. A small number of sites ( 3 in the M.F. John Day and 1 in the

241 Tucannon) which demonstrated highly restricted seasonal fluctuations in stream

242 temperature compared to directly adjacent sites were removed from consideration as

243 these sites were deemed likely to be directly located in groundwater springs

244 representing micro-habitats as opposed to mixed mainstem waters. Instantaneous

245 measures of stream temperature data were summarized to daily mean temperatures.

246 Training datasets were largely distributed evenly across the year while testing datasets

247 were disproportionately represented by summer data, particularly in the M.F. John Day

248 and the Tucannon (Table 1).

249

250

251

252

253

254

255

256

257

258

259

260

261

262

263

264

265

266

267

268

269

270

271

272

273

\section{Spatial and climatic covariates}

A suite of spatial and climatic covariates was considered for stream temperature models (Table 2). Spatial variables were estimated continuously across the basin by stream reach but contained no temporal component. In contrast, climatic variables were temporally continuous (daily values with the exception of Snow April 1st, which was an annual value) but were collected from point source environmental monitoring stations.

All climatic variables were collected from environmental monitoring stations located within watersheds (Figure 1). Air temperature and snowpack data were collected from the environmental monitoring stations with the highest elevation and most continuous time series in each basin as provided by the National Oceanic and Atmospheric Administration's National Centers for Environmental Information (NCEI 2018; https://gis.ncdc.noaa.gov/maps/ncei/summaries/daily). All flow data $(F)$ was collected from the most downstream USGS stream gage in each watershed (USGS 2017; https://waterdata.usgs.gov/nwis/rt). Gaps in coverage of climate variables were filled with a linear spline, though missing data was minimal. Since the effect of air temperature can be delayed due to thermal inertia (Letcher et al. 2016), air temperature was summarized as a time-lagged variable. The primary air temperature variables considered in models represented the average temperature during the three or five day period before the day of interest ( $T 5 a$ and T3a). To limit multicollinearity, information for air temperature on the day of interest was included as the difference between T5a or $T 3 a$ and the mean temperature on the day of interest $(T \Delta a)$. Accordingly, $T \Delta a$ represents if it got colder (negative value) or warmer (positive value) on the day of interest in comparison to prior days. While values of climatic variables in both datasets exhibited substantial interannual variability, variability was largely similar between the two datasets in all cases (e.g., Figures S1-S3).

All spatial variables were estimated for stream reaches segmented at

276

277 confluences within the 2-6th stream order of the 1:24,000 National Hydrography Dataset

278 (NHD, Mckay et al. 2012) using ArcGIS version 10.3 (ESRI 2011). Long reaches were 279 further segmented to a maximum of $3 \mathrm{~km}$. The majority of spatial variables were 
280

281

282

283

284

285

286

287

288

289

290

291

292

293

294

295

296

297

298

299

300

301

302

303

304

305

306

307

308

309

310

311

312

313

314

315

316

317

318

319

summarized by reach specific upstream catchment areas. This creates spatially smoothed predictions as reaches close together have similar catchment areas. To account for the effect of elevation on stream temperature we utilized two variables, the average elevation of the catchment area $(E)$ and the difference between $E$ and the reach specific elevation $(E \Delta)$. Utilizing $E \Delta$ instead of the reach specific elevation reduced multicollinearity. Other spatial variables included the catchment area $(A)$, the Base Flow Index $(B F I)$ as described in the National Hydrography Plus Dataset, the proportion of catchments covered by lakes $(L)$, the reach specific slope $(S L)$, and the percent forest cover of the reach contributing area and entire catchment respectively $(F R / F C)$.

As with most other statistical models for stream temperatures, models depended heavily on the relationship between stream temperature and air temperature. To account for how this relationship changes across space and time, we considered interactions between air temperature ( $T 5 a$ or $T 3 a$ ) and all other variables (spatial and climatic). Interactions between all other variables and day of year $(D)$ were also considered to capture smoother seasonal shifts in relationships that may be resilient to daily fluctuations in air temperature. Variables were allowed to interact with an air temperature variable or $D$, but not both. As higher elevation sites are more directly influenced by seasonal snowpack than low elevation sites, interactions between daily values of snow depth $(S)$ and the average elevation of the catchment $(E)$ were considered. Finally, interactions between the spatial variables of catchment area $(A)$ and catchment elevation $(E)$ were considered to help distinguish between high and low elevation tributary streams, which are likely to have distinct discharge and temperature regimes.

\section{Model fitting and selection}

Two statistical modeling methods, simple linear and general additive models (GAMs, Wood 2006), were used to fit models to stream temperature data from the training datasets (years 2012-2017) for each study watershed (Table 1, Figure 2). To help account for hysteresis in stream temperature, or distinct air/water temperature relationships during the spring warming period due to the influence of snowpack (Harvey et al. 2011, Lisi et al. 2015), separate models were fit to the spring warming period and the fall cooling. While GAM models have the flexibility to account for nonlinear relationships and thus could have been fit to cover the entire year, seasonal models were utilized to allow for comparisons with linear models. The date of the maximum stream temperature in each watershed as predicted by a smoother fit to all data in the training datasets and the first day of the new year were used to split data into distinct spring and fall training datasets (Figure S4). Models were fit to all available data in the respective spring and fall training datasets. 
320

321

322

323

324

325

326

327

328

329

330

331

332

333

334

335

336

337

338

339

340

341

342

343

344

345

346

347

348

349

350

351

352

353

354

355

356

357

358

359

When fitting GAM models, the smoothness, or "wiggliness" of the modeled relationships is controlled by the number of splines, or knots. We manually limited the number of knots as automated techniques, such as penalized regression splines, were found to consistently produce over fit relationships that did not align with hypothesized effects (e.g., Figure S5). All GAM model variables were limited to 3 knots, with the exception of averaged air temperature variables and day of year variables, which were allowed $5 / 4$ knots to account for substantial non-linearity in the relationship air temperature and stream temperature (Mohseni et al. 1998). Explorations found that when more flexibility was given to modeled relationships the resulting models had higher testing dataset prediction error, even if model fits were improved. Interactions in GAM models were fit utilizing the "by" function in R package mgcv, which parameterizes a linear interaction to a smoothed term: $f 1(x 1)^{*} \times 2$ (Wood 2018). We also explored utilizing two way smoothed interactions and tensor product interactions, but found that these options tended to overfit the data (see Wood 2006 for more details).

For model selection we performed a backwards stepwise variable selection procedure. We started by fitting global models including all considered variables and interactions (as listed in Table 3). We found that information criterion, such as AIC or $\mathrm{BIC}$, were not adequate for model selection. Due to the large size of our datasets, these modeling techniques tended to support the inclusion of variables that did not align with hypothesized effects and consequently produced poor testing dataset predictions. Additionally, while our variables contain substantial spatial and temporal information, it is likely that they do not fully account for all spatial and temporal autocorrelation, which may lead to inflated variable significance values (Isaak et al. 2014). To overcome this challenge, climatic, spatial, and interaction terms were retained in linear regression and GAM models only if: 1) their estimated effect aligned with the hypothesized effect of the variable; and 2) the variable was a significant contributor to model performance $(P<$ $0.05)$. Individual variables and interactions that did not meet this criteria were removed one at a time and the model was reassessed at each step until a final model was selected. Variable effects were visualized using the $R$ package visreg (Breheny and Burchett 2017) and compared to hypothesized effects as described briefly in Table 2 and in more depth in the Supplementary Document. Model predictions below zero were changed to zero to represent freezing.

While creating continuous daily predictions provides flexibility in how models could be utilized, many uses will likely involve summarizing daily estimates to specific periods of interest (e.g., mean temperatures during the spawning migration). To explore the effect of temporally aggregating daily predictions on model accuracy we measured the change in prediction accuracy when aggregating daily predictions to monthly predictions of mean stream temperature. All model fitting and subsequent analyses were performed in the statistical computing program $R$ version 3.4.1 ( $R$ Core Team 2014). 
360

361

362

363

364

365

366

367

368

369

370

371

372

373

374

375

376

377

378

379

380

381

382

383

384

385

386

387

388

389

390

391

392

393

394

395

396

\section{Model validation}

Each model was used to predict all available data in the respective training and testing datasets (Figure 2). To validate the accuracy of model predictions we calculated the root mean squared error (RMSE) where $y_{i}$ is the observed value for the ith observation and $\hat{y}_{i}$ is the predicted value;

$$
R M S E=\sqrt{\frac{\sum_{i=1}^{n}\left(\hat{y}_{i}-y_{i}\right)^{2}}{n}}
$$

We calculated three distinct RMSE statistics for each model: 1) For the model fit to the training dataset (RMSE train.), 2) utilizing a leave one site out cross-validation procedure (RMSE C.V.) in which the entire multi-year time series of daily mean stream temperature values from individual sites were left out of the training dataset, then predicted using the resulting models, and 3) for predictions of the testing datasets which was composed of distinct sites and years from the training datasets (RMSE test.). Since we contend that the RMSE test. represents the truest test of the ability of models to account for spatiotemporal dynamics in stream temperature, we focus most of the discussion on this result.

The Nash-Sutcliffe model efficiency coefficient (NSC) was also used to estimate the goodness of predictions, where $\bar{y}$ is the mean stream temperature in the respective testing datasets;

$$
N S C=1-\frac{\sum_{i=1}^{n}\left(\hat{y}_{i}-y_{i}\right)^{2}}{\sum_{i=1}^{n}\left(y_{i}-\bar{y}\right)^{2}}
$$

A NSC value of 1 represents a perfect fit and a negative value suggests the model is worse than using the mean.

\section{Sensitivity Analyses}

Sensitivity analyses of model testing dataset predictions were performed on the selected GAM and linear models, varying both the number of sites and the number of years used in model fits independently. For site sensitivity, selected models with all sites were compared against models fit utilizing data from 10-35 sites at intervals of five, with the exception of the Chiwawa which only contained eleven sites total in the training dataset. For each site count, 100 iterations of randomly chosen site combinations were taken out of the all available sites. Each model was re-fit utilizing only training data from the subset of sites for each iteration and the resulting model was utilized to re-predict the entire testing dataset. The mean RMSE test. for all iterations for each site count 
397

398

399

400

401

402

403

404

405

406

407

408

409

410

411

412

413

414

415

416

417

418

419

420

421

422

423

424

425

426

427

428

429

430

431

432

433

434

435

was estimated. A sensitivity analysis for the number of years required was similarly performed varying the number of years utilized from 3-6.

\section{Results}

\section{Selected climate and spatial variables for estimating stream temperature}

We provide a brief explanation of the variables and interactions found to be useful in describing spatiotemporal patterns in stream temperature in the study watersheds (Table 3 ) and describe these interactions further in the provided Supplementary Document. Covariate relationships with stream temperature that were consistent in importance and form across watersheds are described as "universal" while those that were watershed or model specific are labeled "local".

Climate: Relationships with climatic variables were generally universal in all study basins and largely the same suite of climatic variables and interactions were used across watersheds (Table 3 ). Air temperature ( $T 5 a, T 3 a$, and $T \Delta a$ ), snowpack (S, SA1), flow $(F)$, and day of year $(D)$ variables were all influential in describing spatiotemporal patterns of stream temperature. For air temperature, T5a was the preferred variable in spring models while T3a was selected for fall models. This is likely a consequence of generally lower levels of discharge in the fall, and thus less thermal inertia, leading to a more rapid influence of climatic conditions. For snowpack variables, $S$ interacting with air temperature ( $T 5 a$ or $T 3 a$ ) was generally utilized in fall models, while SA1 interacting with $D$ was utilized in spring models. In fall models, high daily values of $S$ were found to mitigate the effect of air temperature (cooler stream temperatures when it is hot, warmer when it is cold). For spring models $S A 1$ interacting with $D$ helped account for a small cooling effect later into the summer that occurs when snowpack is deep. While we would expect the extent of snowpack to be more influential during the spring warming period due to seasonal snowpack melting, much of this effect was accounted for in the relationship with $F$ interacting with $T 5$ a (Figure 3). Similar to snow depth in the fall models, higher flows were found to relate to mitigated extremes in stream temperature in all spring models and in the fall Wenatchee and Chiwawa models. $F$ was not found to be influential in the with M.F. John Day and Tucannon fall period models, potentially due to mitigating groundwater influences in these dry basins buffering interannual variability in temperature during the low-flow season. The estimated depression in stream temperatures with high discharge during the spring period was stronger than in the fall period, likely as a consequence of this relationship also accounting for the impact of snow melt during this season. 
436 Spatial: In contrast to climatic factors, many spatial relationships were found to have 437 localized importance and smaller networks, the Chiwawa and Tucannon, required fewer 438 spatial covariates. However, catchment area $(A)$ and elevation variables $(E \& E \Delta)$ had 439 universal importance in all watersheds. Due to flow data coming from a point source, $A$

440

441

442

443

444

445

446

447

448

449

450

451

452

453

454

455

456

457

458

459

460

461

462

463

464

465

466

467

468

469

470

471

472

473

474

475 interacting with $E$ helped distinguished high elevation tributaries from lower elevation tributaries, which are likely to become warmer and drier earlier in the season due to lower snowpack influence. $E$ interacting with $D$ described a smoothed seasonal effect of elevation, which was found to have a more substantial cooling effect in the summer in comparison to the winter. A interacting with $F$ was retained in most models and helped distinguished the effect of flow on tributaries of different sizes. Higher values of base flow index $(B F I)$, slope $(S L)$, lakes $(L)$, and forest cover $(F C / F R)$, were associated with cooler stream temperatures at high air temperatures but were only locally important and thus not included in all watershed models. $L$ was not utilized in the M.F. John Day or the Tucannon. However, in the Wenatchee, which contains Lake Wenatchee in the central watershed and thus has a higher proportion of lake area than other watersheds, a strong lake effect was found leading to warmer stream temperatures during summer months.

\section{GAM and linear model performance}

Both GAM and linear Models described spatiotemporal patterns in daily mean stream temperature with high levels of accuracy (RMSE generally $\sim{ }^{\circ} \mathrm{C}$ ) and goodness of fit (NSC generally above 0.9: Table 3 \& Figure 4). Model performance varied amongst watersheds with the Chiwawa and Tucannon models being the most accurate, followed by the Wenatchee models, and the M.F. John Day models having the highest error. Spring models were generally more accurate than fall models as described by all utilized RMSE metrics (average difference $15 \%$ ). The error of the model cross validation tests were similar but slightly higher than the model fits on average, with RMSE train., ranging from 0.62 to $1.46{ }^{\circ} \mathrm{C}$ (spring GAM Chiwawa model to fall linear M.F. John Day model, respectively) and leave one site out cross-validation RMSE C.V., ranging from $0.67^{\circ} \mathrm{C}$ to $1.54^{\circ} \mathrm{C}$ for the same models. When utilizing the models to predict the testing datasets composed of distinct sites and data from different years, prediction error (RMSE test.) was only slightly higher on average compared to RMSE C.V. $(\sim 3 \%)$ and RMSE train $(\sim 17 \%)$, ranging from $1.81^{\circ} \mathrm{C}$ (fall linear M.F John Day model) to $0.70{ }^{\circ} \mathrm{C}$ (spring GAM Chiwawa model), and some models actually performed better. RMSE test. was largely consistent across years in the testing datasets which contained substantial interannual variability in climate (1997-2003 to 2011; Figure 5). Additionally, aggregating daily predictions to monthly predictions markedly increased goodness of fit and reduced RMSE test. in all models by an average of 23\% (Figure 4).

While there was substantially more variability in model performance across watersheds than across modeling techniques, GAM models were generally more 
476

477

478

479

480

481

482

483

484

485

486

487

488

489

490

491

492

493

494

495

496

497

498

499

500

501

502

503

504

505

506

507

508

509

510

511

512

513

514

515

accurate than linear models when all utilized RMSE metrics were compared (average difference $\sim 12 \%$ ). The lone exceptions were the RMSE C.V. values for the spring Wenatchee and fall M.F. John Day models and the RMSE test. value spring Chiwawa linear models (Table 3).

While winter months were generally predicted with comparable precision as described by RMSE Test., they also expressed less variability than warmer months. Consequently, it was actually the summer months in which models described a higher proportion of temperature variability as defined by NSC values (Table 4). In isolated cases during late-fall and winter months models were actually less useful than taking the monthly mean as demonstrated by NSC values below 0 . When isolating for sitespecific predictions of monthly stream temperature, and thus removing all seasonal and spatial patterns, models were generally able to distinguish between colder and warmer years, particularly in summer months exhibiting higher inter-annual variability in stream temperature (e.g., Figure 6).

While the accuracy and precision of dataset predictions were largely consistent across years and models accounted for much of the spatial variability across the landscape (e.g., Figures S6 and S7), some spatial and temporal patterns remained in the model prediction error. For example, when visualizing the prediction error over time for selected Wenatchee sites from the training dataset (Site WC503432-000155, Peshastin Creek) and the testing dataset (Site \# 219, Nason Creek), we saw clear seasonal patterns in residuals that repeat across predicted years (Figure 7). These two sites were chosen for presentation because they had near median prediction error (RMSE) compared to all sites in the Wenatchee models. Consequently, they are fairly representative of the form and magnitude of residual patterns seen at other sites. In the case of the Peshastin Creek site in the training dataset, the selected GAM models tend to under-predict temperatures in the spring through early fall (Figure 7a). In contrast, testing dataset predictions at the Nason Creek site tended to be too low in the summer (Figure 7b). However, as is the case for most sites, predicted temperatures largely remain a degree or two degrees from measured temperatures throughout the entire multi-year time series.

\section{Sensitivity analyses}

While selected GAM models produced better predictions than linear models, accuracy of GAM models degraded more quickly when the number of years and sites was reduced (Table 5). We believe GAM models degraded more quickly due to their flexibility combined with no re-examination of the theoretical basis of the fitted relationships in the sensitivity analysis due to automation of the process. We therefore focus our discussion on the sensitivity results for linear models as this is likely a better representation of the amount of data required to achieve desired model accuracy. Linear model sensitivity to the number of sites depended on the watershed, but no 
516 sensitivity analysis for the number of sites was done for the Chiwawa since this 517 watershed only contained 11 sites. Increases in RMSE test. of over $10 \%$ occurred in 518 the Wenatchee models when sites were reduced to 20, in the M.F. John Day models 519 when sites were removed down to 15 , and in the Tucannon models when sites were 520 reduced down to 10 . For the sensitivity test for the number of years, increases only 521 surpassed $10 \%$ when reducing each tested time series from 6 years to 3 years. Note 522 that sensitivity analyses were likely conservative since the vast majority of sites were 523 not operational for the entire duration of the fitting time-series (Table 5), and if temporal coverage of fitting sites was higher, we would expect lower site requirements.

525

526

527

\section{Discussion}

528

529

\section{Interactions and modeling performance}

530

531

Climate interacts with spatial heterogeneity on the landscape to produce complex spatiotemporal patterns in stream temperature across watersheds. Our results suggest

532 that much of the variability inherent in this complex process can be approximated in

533 statistical models by utilizing simple interactions terms between spatial and climatic

534 variables. Dependent on these interactions, both GAM and simple linear models

535 predicted spatiotemporal patterns in daily mean values of stream temperature across all

536 four of the complex mountainous study watersheds with a level of accuracy and

537 precision which compares well to other modeling studies with similar objectives (McNyset et al. 2015, Turschwell et al. 2016, Jackson et al. 2017). Additionally, the

539 ability of models to predict stream temperature at distinct sites and years compared to

540 what was utilized in fitting provides increased confidence that models capture

541 interactions that drive seasonal and interannual variability in stream temperature, as

542 opposed to unique patterns present within a dataset. This result suggests that by accounting for interactions, models are not only capable of providing quality estimates of stream temperature throughout the spatial and temporal extent of a monitoring network, but could be utilized to fill temporal and spatial monitoring gaps and to extend time series when logger data is limited.

The consistency in form and importance of the climatic relationships across the study watersheds suggests the presented methodology for parameterizing the effect of climate may be widely applicable. While the models as fit are only applicable to their respective basins, we saw largely consistent form in the modeled effects of climatic variables across all study watersheds. Three commonly cited challenges of modeling

552 the influence of climate on stream temperature include hysteresis, temporal autocorrelation, and the temporally lagged influence of air temperature (Letcher et al. 2016). These issues are often described as independent processes and are addressed with distinct modeling techniques (e.g., distinct spring/fall models, temporal 
556

557

558

559

560

561

562

563

564

565

566

567

568

569

570

571

572

573

574

575

576

577

578

579

580

581

582

583

584

585

586

587

588

589

590

591

592

593

594

595

autocorrelation, air temperature time lags). However, each of these challenges is largely a consequence of the difficulty in accounting for spatial and temporal variation in the thermal inertia of streams which affects the rate at which water temperatures respond to influences such as heat transfer with the surrounding environment and solar radiation (Caissie 2006). Thermal inertia varies spatially with channel form and stream size (Stefan and Preud'homme 1993) and temporally with discharge levels (Smith and Lavis 1975, Webb et al. 2003). Similarly, the influence of snowpack melt, which depresses stream temperatures, also varies spatially and temporally, both seasonally and interannually (Lisi et al. 2015). The ability of models to capture the dynamic nature of thermal inertia and the influence of snowpack with static variables or autocorrelation techniques which don't vary across time and space is likely to be limited. However, while there is still room for improvement, our results suggest that including parameters incorporating the separate effects of discharge, snowpack, and air temperature and interaction terms accounting for the interdependency of these variables can be largely successful in this challenge.

Other spatiotemporal statistical modeling studies of stream temperature that depend on hierarchical and autocorrelation modeling techniques tend to see large increases in error when temporally expanding predictions beyond the range of the fitting data. This suggests that a major driver of stream temperature is not parameterized in the covariates. For example, Hocking et al. (2018) used a number of variables, interactions, random effects and an AR1 process to model stream temperature in the northeastern United States and saw an increase in RMSE from $0.59{ }^{\circ} \mathrm{C}$ for the training dataset to $2.06{ }^{\circ} \mathrm{C}$ when predicting the same sites but distinct years. While their model did attempt to account for variation in discharge and air temperature, it did not account for snowpack and depended heavily on a static AR1 process (AR1 $=0.77$ ). We saw a proportionally much smaller decline in precision when predicting distinct years (average RMSE train. to average RMSE test., 1.02 to $1.20^{\circ} \mathrm{C}$ ). This demonstrates the value of a full exploration of variables and interactions to account for spatiotemporal mechanisms.

Remaining patterns in our residuals suggest that our model fits could still be improved, potentially by accounting for autocorrelation. While well parameterized variables may be able to capture many of the physical forces that cause spatial and temporal autocorrelation in stream temperature, such as water volume/flow rates and the influence of snowpack, statistically parameterized variables are never likely to be perfect at this task given the complexity of climate/spatial influences that determine spatiotemporal patterns. However, all models would be improved by explanatory variables that better capture the dynamic influences on stream temperature. Numerous past studies have compared non-spatial models to spatial modeling techniques with non-spatial models generally performing poorly (e.g., Isaak et al. 2010, Turschwell et al. 2016). This has led to a general conclusion that non-spatial models are limited in their ability to predict complex patterns in stream temperature, particularly on shorter time 
596

597

598

599

600

601

602

603

604

605

606

607

608

609

610

611

612

613

614

615

616

617

618

619

620

621

622

623

624

625

626

627

628

629

630

631

632

633

634

scales such as daily measurements (Benyahya et al. 2007). However, our results demonstrate that even simple linear models are capable of producing relatively precise predictions assuming that a more comprehensive and effective list of covariates and interactions are parameterized.

Models generally described the majority of variability in stream temperature during warmer weather months (generally April-October) but were less useful in colder weather months. Due to the dependence of models on the influence of air temperature, models may be less able to describe variability as the relationship between air and stream temperature flattens as air temperatures approach freezing (Mohseni et al. 1998). Since the study basins experienced extended periods of time at below freezing air temperatures during the winter, stream temperatures had little variation across basins during these cold-weather months. If the winter is not of interest, the development of models could be restricted to exclude the winter period, as done by Letcher et al. (2016). However, due to higher variability in temperature during the summer in comparison to the winter (Figure S4), winter-specific relationships may have also been overshadowed by summer variability. If winter temperatures are of concern, generating winter-specific models would potentially improve temperature predictions for this period.

GAM models generally outperformed linear models, particularly in the larger basins of the Wenatchee and the M.F. John Day. This is likely due to their ability to easily capture non-linear relationships, such as between air temperature and stream temperature (Holthuijzen 2017), which may be more useful in more complex watersheds. Larger watersheds contain a wider variation in explanatory variable values and thus are more likely to include variable values that fall in the non-linear range of variable effects. Due to their better performance, we suggest utilizing GAM models over linear models, though we reiterate the need to highly restrict knots to prevent overfitting. Additionally, GAM relationships should be visualized to ensure that they align with hypothesized effects. Given a time series of four or more years, the ability of models to capture factors affecting interannual variability could be tested with a leave-one-year-out cross-validation procedure.

Models fit to smaller watersheds, such as the Chiwawa, or simpler networks, such as in the Tucannon, produced more accurate predictions and sensitivity analysis suggested that these watersheds required fewer sites. This result is not surprising as larger watersheds generally encompass higher variation in river/landscape characteristics which create challenges to modeling. Fewer sites per watershed than suggested by the sensitivity analysis would likely be required if training datasets contained fewer gaps and if logger locations were chosen to cover spatial gradients (Marsha et al. 2018). Sensitivity analyses suggested that at least four years of data was sufficient; however, including longer time-series and more diverse climate years would 
635 increase confidence in the ability of models to capture the influence of interannual 636 climatic variability.

637 The accuracy of temperature predictions increased markedly when aggregating 638 from daily values to mean monthly values, suggesting that the accuracy of the daily 639 predictions can be considered a minimum for aggregated predictions. This result is not 640 surprising as stream temperature has long been shown to be more directly correlated 641 with air temperature at larger time scales (e.g., weekly and monthly) compared to daily

642 values (Pilgrim and Fang 1998). Aggregating smooths out daily error caused by

643 imperfect parameterization of thermal inertia and climate effects leading to mistimed or 644 under/over predicted changes in temperature.

\section{Model utility and potential improvements}

Continuous predictions of stream temperature allow biologist and watershed managers to examine the effects of stream temperature throughout the entire year and to create temporally and spatially tailored summary metrics to a life stage or period of interest (e.g., mean temperatures during egg incubation or smolting). The level of accuracy of model predictions and the demonstrated ability of models to account for interannual variability in climatic influences is likely to be useful to biologists and watershed managers. As described above, spatially and temporally aggregating daily predictions to a period of interest is likely to improve accuracy and precision. The ability to expand predictions temporally and spatially suggests that such statistical models could be utilized to extend time series or fill-in monitoring gaps following the collection of enough data for parameterization, potentially reducing the requirements for effective long-term monitoring.

The ability of the models to successfully predict diverse climate years suggests that this approach may be effective for assessing the consequences of climate change. Climate change will cause increases in air temperature as well as significant reductions in snowpack, leading to earlier spring runoff and lower summer flows in the Pacific Northwest (Wu et al. 2012, Tohver et al. 2014). We demonstrate substantial impacts of air temperature, discharge, and snowpack as well as of the interactions between these variables and spatial effects on stream temperature. Consequently, models that do not account for all three of these variables and associated interactions are not likely to produce accurate climate change predictions. Estimates of changes in snowpack (e.g., Lute et al. 2015), stream discharge (e.g., Chegwidden et al. 2017), and air temperature (e.g., RMJOC 2018) as a consequence of climate change are widely available for the inclusion in future modeling efforts.

While results are encouraging, there are a number of ways that models could potentially be improved. As described above, the addition of autocorrelation methods to account for remaining patterns in residuals should be explored. The inclusion of autocorrelation techniques may allow for the use of statistical model selection (e.g., 
675 AIC), which we found to be overly permissive in our variable selection process. Models 676 that don't fully account for the interrelatedness of data points, either through variables or 677 autocorrelation techniques, may demonstrate inflated variable significance (Isaak et al.

678 2014). Improvements may also come from continued advancements in variable 679 parameterization, for example, the inclusion of spatial variables that more thoroughly 680 account for local stream characteristics impacting stream temperature (Holtby 1988, 681 Johnson 2004, Caissie 2006), such as reach-specific shading, solar radiation, and 682 groundwater influences (McNyset et al. 2015, Turschwell et al. 2016, Isaak et al. 683 2017b). These localized factors have a substantial influence on stream temperature 684 (Holtby 1988, Johnson 2004, Caissie 2006) which can occur within short reaches 685 (Johnson 2004). As currently constructed, models are basin specific as environmental relationships are fit relative to measurements at the specific environmental monitoring stations. Incorporating spatially explicit estimates of climate variables instead of data from point sources would potentially improve general applicability of models since environmental values would be specific to each stream segment (e.g., DayMet in Hocking et al. 2018). Spatially explicit climate variables would also reduce the need to include interactions to describe variation in climate effects across space, thereby allowing for simpler models and interpretation.

\section{Conclusions}

The determinants of spatiotemporal patterns in stream temperature are complex, driven by seasonal and interannual climate variability interacting with diverse landscapes. Our results suggest that the inclusion of variable interactions in statistical models based on mechanistic principles can produce accurate stream temperature predictions across space and time. We demonstrate that this can be achieved with simple modeling techniques informed by easy to parameterize variables developed from widely available environmental and geographical information. These methods allow for the filling of temporal gaps in stream temperature monitoring records and the ability to predict unmonitored years. However, a level of remaining patterns in residuals suggest that this methodology could still be improved, either through the inclusion of methods to account for autocorrelation or the parameterization of missing variable influences. We have suggested a number of potential improvements that we believe will increase the precision of predictions, reduce the need for separate seasonal fall and spring models, and make models more generally applicable across larger spatial regions and levels of climate variability.

\section{Acknowledgements}


715

716

717

718

719

720

721

722

723

724

725

726

727

728

729

730

731

732

733

734

735

736

737

738

739

740

741

742

743

744

745

746

747

748

749

750

751

752

753

754

755

756

757

758

759

We thank Kris McNyset for performing much of the foundational work that this project was based on. Thanks to Arielle Gervasi and Jesse Langdon for GIS processing. Thanks to Chris Jordan for a friendly review. Finally, thanks to Aimee Fullerton for productive discussions, feedback and insights.

\section{References}

Arismendi, I., S. L. Johnson, J. B. Dunham, and R. Haggerty. 2013. Descriptors of natural thermal regimes in streams and their responsiveness to change in the Pacific Northwest of North America. Freshwater Biology 58:880-894.

Arismendi, I., M. Safeeq, J. B. Dunham, and S. L. Johnson. 2014. Can air temperature be used to project influences of climate change on stream temperature? Environmental Research Letters 9.

Arrigoni, A. S., G. C. Poole, L. A. K. Mertes, S. J. O. Daniel, W. W. Woessner, and S. A. Thomas. 2008. Buffered, lagged, or cooled? Disentangling hyporheic influences on temperature cycles in stream channels. Water Resources Research 44:13pp.

Ashley Steel, E., C. Sowder, and E. E. Peterson. 2016. Spatial and temporal variation of water temperature regimes on the Snoqualmie River network. JAWRA Journal of the American Water Resources Association 52:769-787.

Beacham, T. D., and C. B. Murray. 1990. Temperature, egg size, and development of embryos and alevins of five species of Pacific Salmon: A comparative analysis. Transactions of the American Fisheries Society 119:927-945.

Benyahya, L., D. Caissie, A. St-Hilaire, T. B. M. J. Ouarda, and B. Bobée. 2007. A review of statistical water temperature models. Canadian Water Resources Journal 32:179-192.

Bowerman, T., A. Roumasset, M. L. Keefer, C. S. Sharpe, and C. C. Caudill. 2017. Prespawn mortality of female Chinook salmon increases with water temperature and percent hatchery origin. Transactions of the American Fisheries Society 147:31-42.

Breheny, P., and W. Burchett. 2017. Visualization of regression models using visreg. The R Journal 9:56-71.

Caissie, D. 2006. The thermal regime of rivers: A review. Freshwater Biology 51:1389_ 1406.

Caissie, D., M. G. Satish, and N. El-Jabi. 2007. Predicting water temperatures using a deterministic model: Application on Miramichi River catchments (New Brunswick, Canada). Journal of Hydrology 336:303-315.

Chegwidden, O. S., D. E. Nijssen, D. E. Rupp, and P. W. Mote. 2017. Hydrologic response of the Columbia River system to climate change [Data set]. http://hydro.washington.edu/CRCC/.

Crozier, L. G., M. D. Scheuerell, and R. W. Zabel. 2011. Using time series analysis to characterize evolutionary and plastic responses to environmental change: A case study of a shift toward earlier migration date in sockeye salmon. American

Peer] reviewing PDF | (2019:03:36199:1:1:NEW 2 Aug 2019) 
760

761

762

763

764

765

766

767

768

769

770

771

772

773

774

775

776

777

778

779

780

781

782

783

784

785

786

787

788

789

790

791

792

793

794

795

796

797

798

799

800

801

802

803

804

805

Naturalist 178:755-773.

Crozier, L. G., R. W. Zabel, E. E. Hockersmith, and S. Achord. 2010. Interacting effects of density and temperature on body size in multiple populations of Chinook salmon. Journal of Animal Ecology 79:342-349.

Ebersole, J. L., W. J. Liss, and C. A. Frissell. 2003. Thermal heterogeneity, stream channel morphology, and salmonid abundance in northeastern Oregon streams. Canadian Journal of Fisheries \& Aquatic Sciences 60:1266-1280.

ESRI. 2011. ArcGIS. Environmental Systems Research Institute (ESRI).

Fullerton, A. H., C. E. Torgersen, J. J. Lawler, R. N. Faux, E. A. Steel, T. J. Beechie, J. L. Ebersole, and S. G. Leibowitz. 2015. Rethinking the longitudinal stream temperature paradigm: region-wide comparison of thermal infrared imagery reveals unexpected complexity of river temperatures. Hydrological Processes 4737:4719_ 4737.

Hocking, D. J., K. O. Neil, and B. H. Letcher. 2018. A hierarchical model of daily stream temperature for regional predictions. Peer J Pre print:1-27.

Holtby, L. B. 1988. Effects of Logging on Stream Temperatures in Carnation Creek British Columbia, and Associated Impacts on the Coho Salmon ( Oncorhynchus kisutch ). Canadian Journal of Fisheries and Aquatic Sciences 45:502-515.

Holthuijzen, M. F. 2017. A Comparison of Five Statistical Methods for Predicting Stream Temperature Across Stream Networks. All Graduate Theses and Dissertations 6535.

Isaak, D. J., E. E. Peterson, J. M. Ver Hoef, S. J. Wenger, J. A. Falke, C. E. Torgersen, C. Sowder, E. A. Steel, M.-J. Fortin, C. E. Jordan, A. S. Ruesch, N. Som, and P. Monestiez. 2014. Applications of spatial statistical network models to stream data. WIREs Water 1:277-294.

Isaak, D. J., S. J. Wenger, E. E. Peterson, J. M. Ver Hoef, D. E. Nagel, C. H. Luce, S. W. Hostetler, J. B. Dunham, B. B. Roper, S. P. Wollrab, G. L. Chandler, D. L. Horan, and S. Parkes-Payne. 2017a. The NorWeST Summer Stream Temperature Model and Scenarios for the Western U.S.: A Crowd-Sourced Database and New Geospatial Tools Foster a User-Community and Predict Broad Climate Warming of Rivers and Streams. Water Resources Research 53.

Isaak, D. J., S. J. Wenger, E. E. Peterson, J. M. Ver Hoef, D. E. Nagel, C. H. Luce, S. W. Hostetler, J. B. Dunham, B. B. Roper, S. P. Wollrab, G. L. Chandler, D. L. Horan, and S. Parkes-Payne. 2017b. The NorWeST Summer Stream Temperature Model and Scenarios for the Western U.S.: A Crowd-Sourced Database and New Geospatial Tools Foster a User Community and Predict Broad Climate Warming of Rivers and Streams. Water Resources Research 53:9181-9205.

Isaak, D. J., S. Wollrab, D. Horan, and G. Chandler. 2012. Climate change effects on stream and river temperatures across the northwest U.S. from 1980-2009 and implications for salmonid fishes. Climatic Change 113:499-524.

Isaak, D. J., M. K. Young, C. H. Luce, S. W. Hostetler, S. J. Wenger, E. E. Peterson, J. M. Ver Hoef, M. C. Groce, D. L. Horan, and D. E. Nagel. 2016. Slow climate velocities of mountain streams portend their role as refugia for cold-water biodiversity. Proceedings of the National Academy of Sciences 113:4374-4379.

Isaak, D., C. Luce, B. Rieman, D. Nagel, E. Peterson, D. Horan, S. Parkes, and G. Chandler. 2010. Effects of Climate Change and Recent Wildfires on Stream

Peer) reviewing PDF | (2019:03:36199:1:1:NEW 2 Aug 2019) 
806

807

808

809

810

811

812

813

814

815

816

817

818

819

820

821

822

823

824

825

826

827

828

829

830

831

832

833

834

835

836

837

838

839

840

841

842

843

844

845

846

847

848

849

850

851

Temperature and Thermal Habitat for Two Salmonids in a Mountain River Network. Ecological Applications 20:1350-1371.

ISEMP/CHaMP. 2017. Integrated Status and Effectiveness Monitoring Program (ISEMP) and Columbia Habitat Monitoring Program (CHaMP) Annual Combined Technical Report, January-December 2016, BPA Projects 2003-017-00 and 2011006-00, 93 Electronic Pages.

Jackson, F. L., R. J. Fryer, D. M. Hannah, C. P. Millar, and I. A. Malcolm. 2018. A spatio-temporal statistical model of maximum daily river temperatures to inform the management of Scotland's Atlantic salmon rivers under climate change. Science of the Total Environment 612:1543-1558.

Jackson, F. L., D. M. Hannah, R. J. Fryer, C. P. Millar, and I. A. Malcolm. 2017. Development of spatial regression models for predicting summer river temperatures from landscape characteristics: Implications for land and fisheries management. Hydrological Processes 31:1225-1238.

Johnson, S. L. 2004. Factors influencing stream temperatures in small streams: substrate effects and a shading experiment. Canadian Journal of Fisheries and Aquatic Sciences 61:913-923.

Kaushal, S. S., G. E. Likens, N. A. Jaworski, M. L. Pace, A. M. Sides, D. Seekell, K. T. Belt, D. H. Secor, and R. L. Wingate. 2010. Rising stream and river temperatures in the United States. Frontiers in Ecology and the Environment 8:461-466.

Lawrence, D. J., B. Stewart-Koster, J. D. Olden, A. S. Ruesch, C. E. Torgersen, J. J. Lawler, D. P. Butcher, and J. K. Crown. 2014. The interactive effects of climate change, riparian management, and a nonnative predator on stream-rearing salmon. Ecological Applications 24:895-912.

Letcher, B. H., D. J. Hocking, K. O'Neil, A. R. Whiteley, K. H. Nislow, and M. J. O'Donnell. 2016. A hierarchical model of daily stream temperature using air-water temperature synchronization, autocorrelation, and time lags. PeerJ 4:e1727.

Li, H., X. Deng, D.-Y. Kim, and E. P. Smith. 2014. Modeling maximum daily temperature using a varying coefficient regression model. Water Resources Research 50:30733087.

Lisi, P. J., D. E. Schindler, T. J. Cline, M. D. Scheuerell, and P. B. Walsh. 2015. Stream Thermal Sensitivity To Air Temperature. Geophysical Research Letters 42:33803388.

Luce, C. H., and Z. A. Holden. 2009. Declining annual streamflow distributions in the Pacific Northwest United States, 1948-2006. Geophysical Research Letters 36:16.

Luce, C., B. Staab, M. Kramer, S. Wenger, D. Isaak, and C. McConnell. 2014. Sensitivity of summer stream temperatures to climate variability in the Pacific Northwest. Water Resources Research 50:3428-3443.

Lute, A. C., J. T. Abatzoglou, and K. C. Hegewisch. 2015. Projected changes in snowfall extremes and interannual variability of snowfall in the western United States. Water Resources Research:960-972.

Marsha, A., E. A. Steel, A. H. Fullerton, and C. Sowder. 2018. Monitoring riverine thermal regimes on stream networks: Insights into spatial sampling designs from the Snoqualmie River, WA. Ecological Indicators 84:11-26.

Mauger, S., R. Shaftel, J. C. Leppi, and D. J. Rinella. 2017. Summer temperature 
852

853

854

855

856

857

858

859

860

861

862

863

864

865

866

867

868

869

870

871

872

873

874

875

876

877

878

879

880

881

882

883

884

885

886

887

888

889

890

891

892

893

894

895

896

897

regimes in southcentral Alaska streams: watershed drivers of variation and potential implications for Pacific salmon. Canadian Journal of Fisheries and Aquatic Sciences 74:702-715.

Mayer, T. D. 2012. Controls of summer stream temperature in the Pacific Northwest. Journal of Hydrology 475:323-335.

McNyset, K. M., C. J. Volk, and C. E. Jordan. 2015. Developing an effective model for predicting spatially and temporally continuous stream temperatures from remotely sensed land surface temperatures. Water (Switzerland) 7:6827-6846.

Mohseni, O., H. G. Stefan, and T. R. Erickson. 1998. A nonlinear regression model for weekly stream temperatures. Water Resources Research 34:2685-2692.

National Center for Environmental Information (NCEI). 2018. Daily Summaries Map. https://gis.ncdc.noaa.gov/maps/ncei/summaries/daily.

Pankhurst, N. W., and P. L. Munday. 2011. Effects of climate change on fish reproduction and early life history stages. Marine And Freshwater Research 62:1015-1026.

Peterson, E., J. Ver Hoef, D. J. Isaak, J. A. Falke, M.-J. Fortin, E. Jordan, K. Mcnyset, P. Monestiez, A. S. Ruesch, A. Sengupta, N. Som, A. E. Steel, D. M. Theobald, C. E. Torgensen, and S. J. Wenger. 2013. Modelling dendritic ecological networks in space: an integrated network perspective. Ecological Letters 16:707-719.

Pilgrim, J. M., and X. Fang. 1998. Stream temperature correlations with air temperatures. Journal of the American Water Resources Association 34:11091121.

R Core Team. 2014. R: A language for environmental and statistical computing. $R$ Foundation for Statistical Computing, Vienna, Austria.

Riedel, J., and M. A. Larrabee. 2016. Impact of Recent Glacial Recession on Summer Streamflow in the Skagit River Impact of Recent Glacial Recession on Summer Streamflow in the. Norwest Science 90:5-22.

River Management Joint Operating Committee (RMJOC-II). 2018. Climate and hydrology datasets for RMJOC long-term planning studies: Second Edition (RMJOC-II) Part I: Hydroclimate projections and analyses.

Ruesch, A. S., C. E. Torgersen, J. J. Lawler, J. D. Olden, E. E. Peterson, C. J. Volk, and D. J. Lawrence. 2012. Projected Climate-Induced Habitat Loss for Salmonids in the John Day River Network, Oregon, U.S.A. Conservation Biology 26:873-882.

Segura, C., P. Caldwell, G. Sun, S. Mcnulty, and Y. Zhang. 2015. A model to predict stream water temperature across the conterminous USA. Hydrological Processes 29:2178-2195.

Sinokrot, B. A., and J. S. Gulliver. 2014. In-Stream Flow Impact on River Water Temperatures In-stream flow impact on river water temperatures. Journal of Hydraulic Research 38:339-350.

Smith, K., and M. E. Lavis. 1975. Environmental influences on the temperature of a small upland stream. Oikos 26:228-236.

Steel, E. A., C. Sowder, and E. E. Peterson. 2016. Spatial and Temporal Variation of Water Temperature Regimes on the Snoqualmie River Network. JAWRA Journal of the American Water Resources Association 52:769-787.

Stefan, H. G., and E. B. Preud'homme. 1993. Stream temperature estimation from air temperature. Journal of the American Water Resources Association 29:27-45. 
898

899

900

901

902

903

904

905

906

907

908

909

910

911

912

913

914

915

916

917

918

919

920

921

922

923

924

925

926

927

928

929

930

Sykes, G. E., and J. M. Shrimpton. 2010. Effect of temperature and current manipulation on smolting in Chinook salmon (Oncorhynchus tshawytscha): the relationship between migratory. Canadian Journal of Fisheries \& Aquatic Sciences 201:191-201.

Tohver, I. M., A. F. Hamlet, and S. Y. Lee. 2014. Impacts of 21st-Century Climate Change on Hydrologic Extremes in the Pacific Northwest Region of North America. Journal of the American Water Resources Association 50:1461-1476.

Turschwell, M. P., E. E. Peterson, S. R. Balcombe, and F. Sheldon. 2016. To aggregate or not? Capturing the spatio-temporal complexity of the thermal regime. Ecological Indicators 67:39-48.

United States Geological Survey. 2017. National Water Information System: Web Interface. https://waterdata.usgs.gov/nwis/rt.

Vannote, R. L., G. W. Mishall, K. W. Cummins, J. R. Sedell, and C. E. Cushing. 1980. The river continuum concept. Canadian Journal of Fish and Aquatic Science 37:130-137.

Webb, B. W., P. D. Clack, and D. E. Walling. 2003. Water-air temperature relationships in a Devon river system and the role of flow. Hydrological Processes 17:30693084.

Webb, B. W., D. M. Hannah, R. D. Moore, L. E. Brown, and F. Nobilis. 2008. Recent advances in stream and river temperature research. Hydrologic Processes 22:902918.

Winfree, M. M., E. Hood, S. L. Stuefer, D. E. Schindler, T. J. Cline, C. D. Arp, and S. Pyare. 2018. Landcover and geomorphology influence streamwater temperature sensitivity in salmon bearing watersheds in Southeast Alaska. Environmental Research Letters 13:064034.

Wood, S. 2018. mgcv: Mixed GAM Computation Vehicle with Automatic Smoothness Estimation. https://cran.r-project.org/web/packages/mgcv/mgcv.pdf.

Wood, S. N. 2006. Generalized additive models: an introduction with R. 1st edition. CRC Press, London, United Kingdom.

Wu, H., J. S. Kimball, M. M. Elsner, N. Mantua, R. F. Adler, and J. Stanford. 2012. Projected climate change impacts on the hydrology and temperature of Pacific Northwest rivers. Water Resources Research 48:1-23. 


\section{Figure 1}

Map of study basins and environmental data collection sites

Maps of study watersheds showing the stream logger sites used for model training and model testing datasets for the Wenatchee/Chiwawa (A), the M.F. John Day (B), and the Tucannon. The location of stream gages and climatic stations where data for environmental covariates were collected are also shown. Due to limitations in the spatial distribution of site coverage in the M.F. John Day and the Tucannon, the modeled stream networks were restricted to the upper basin and mainstem channel respectively. 


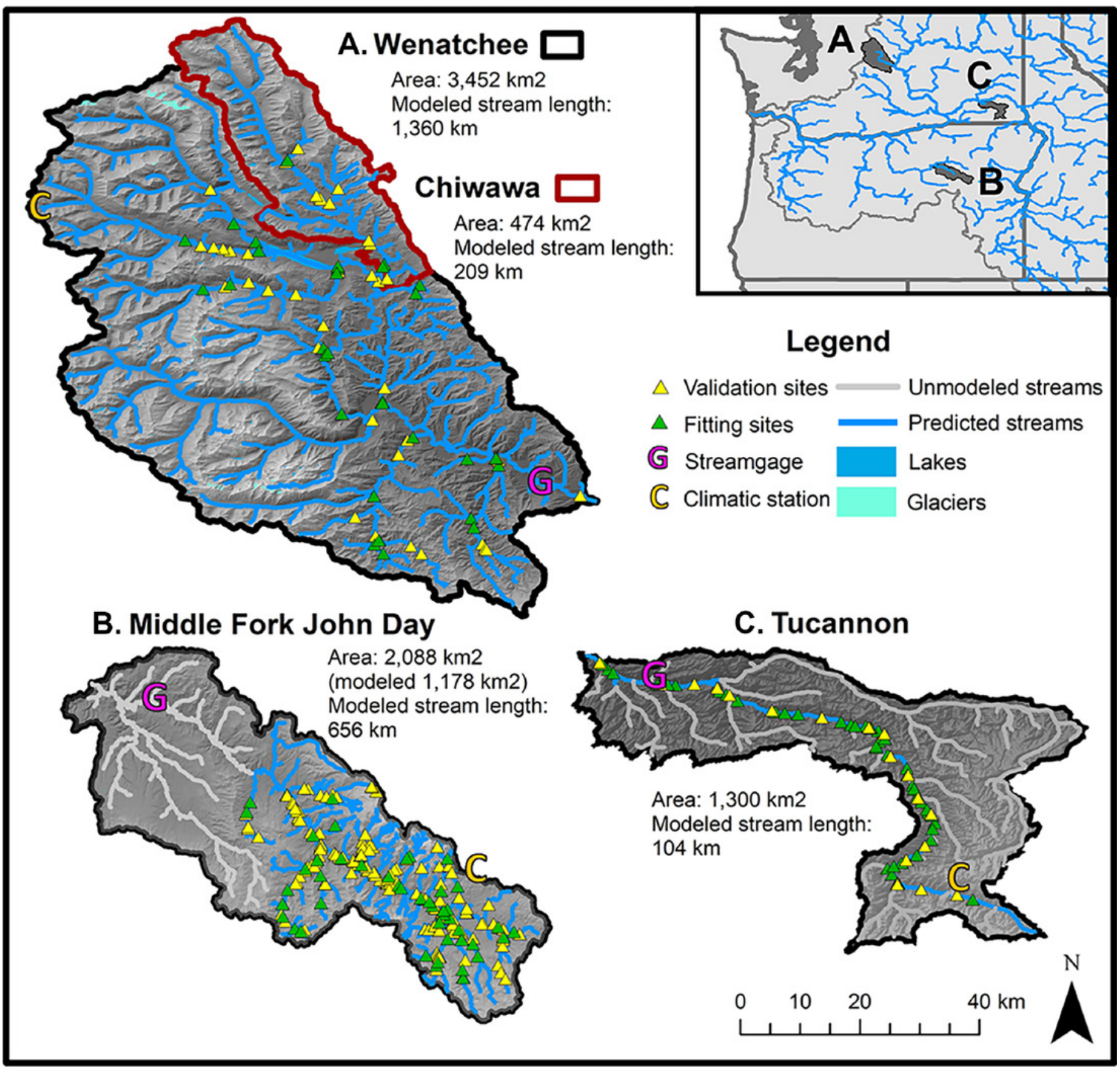


Figure 2

Model fit and validation years for each study basin

Representation of study methodology: Seasonal models (spring and fall) were fit across all years of data in training datasets (2012-2017). Models were subsequently used to predict daily data in the testing datasets (1997-2011) in the Wenatchee, Chiwawa, M.F. John Day, and Tucannon river basins.

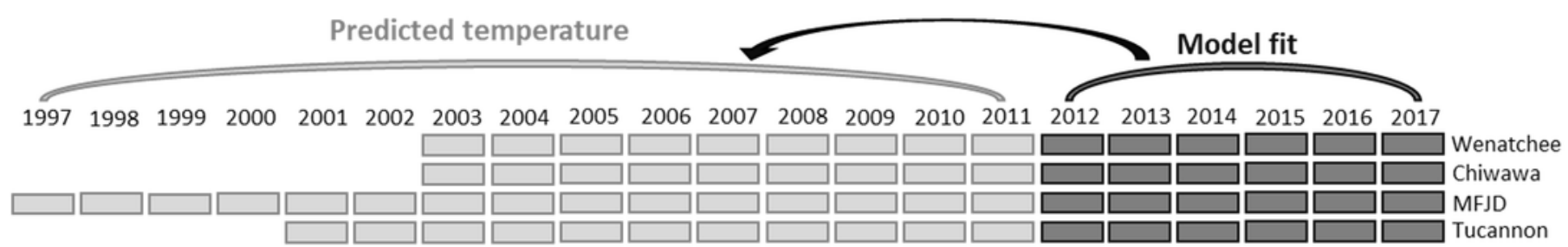




\section{Figure 3}

Example of interaction effect on stream temperature (flow and air temperature)

Conditional surface plots showing the modeled effects of averaged air temperature variables (T5a and T3a) interacting with flow $(F)$ on stream temperature (Tw) for the best spring (A-D) and fall models (E-F) from each of the study watersheds. This effect was not retained in the M.F. John Day and the Tucannon fall models. Relationships are presented holding all other variables in models at median values.

A. Spring Wenatchee

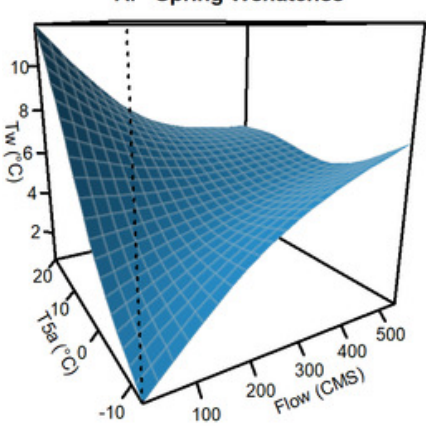

E. Fall Wenatchee

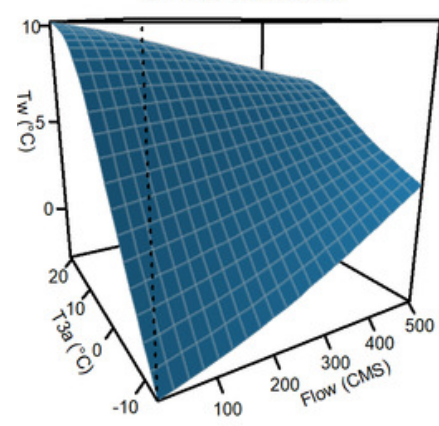

B. Spring Chiwawa

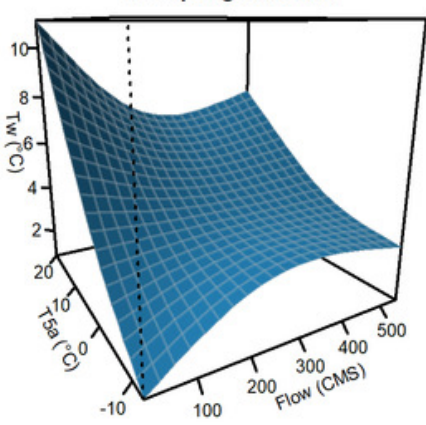

F. Fall Chiwawa

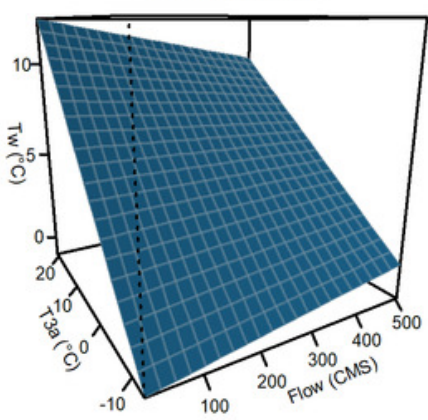

C. Spring MFJD

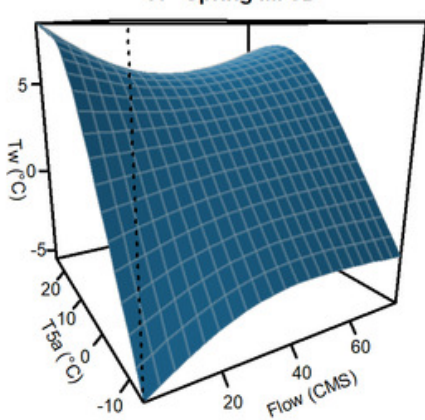

20 FION $(C M S)$
D. Spring Tucannon

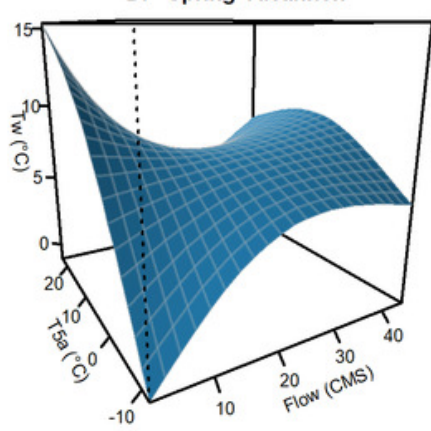


Figure 4

Model validation prediction accuracy results

Graphs showing the accuracy of the best validation predictions (linear or GAM) for combined fall and spring models versus measured daily (A-D) and monthly (E-G) measurements of stream temperature. Testing dataset prediction statistics are shown for each watershed including the root mean squared error (RMSE Test.), the mean absolute error (MAE), and the Nash-Sutcliffe Coefficient (NSC Test.).
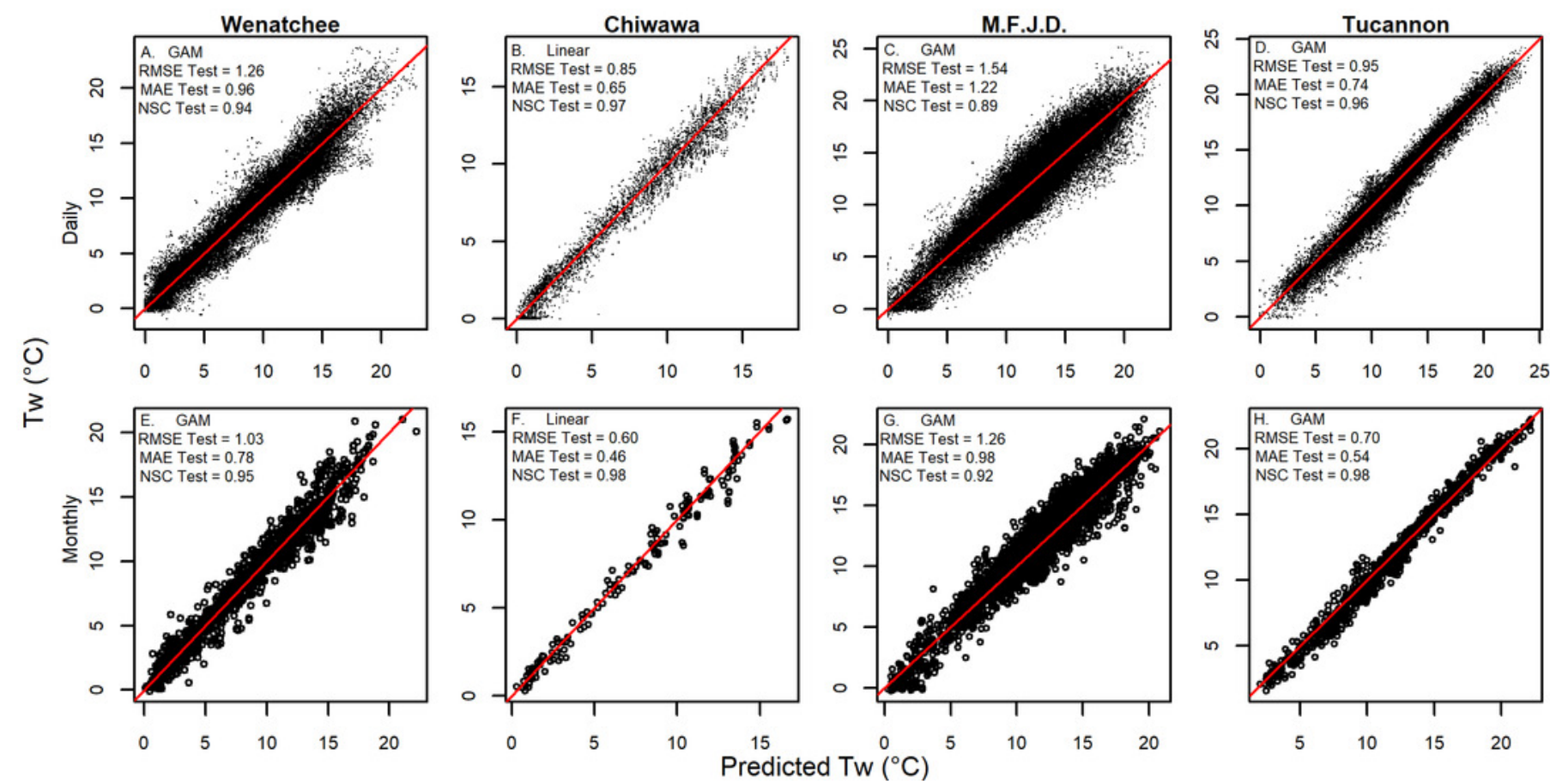


\section{Figure 5}

\section{Predicion accuracy by year}

Graphs showing daily testing dataset model predictions versus measured stream

temperature by year in the Wenatchee (A-I), Chiwawa (J-R), M.F. John Day (S-JJ) and Tucannon (HH-RR) watersheds. The root mean squared error for the testing datasets predictions by year (RMSE test.) are also shown. 


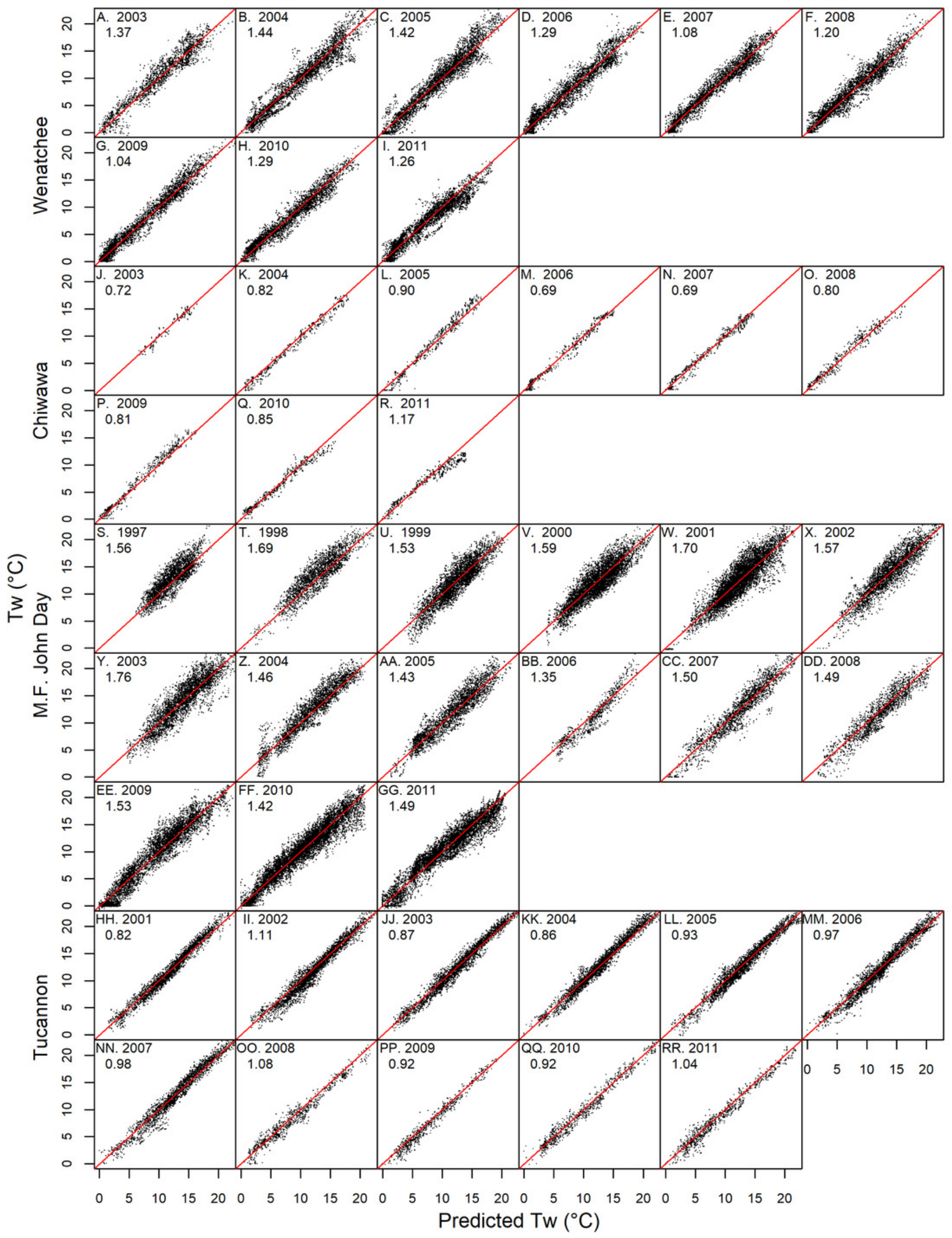


Figure 6

The ability of models to distinguish between years by month

Monthly aggregated testing dataset model predictions from selected GAM models shown versus measured temperatures by month for the two sites with the Wenatchee with the most continuous time series of data (located in Nason Creek [red circles] and Peshastin Creek [blue triangles]). Note, the range of axes vary by month to better show variability between predictions and measurements.
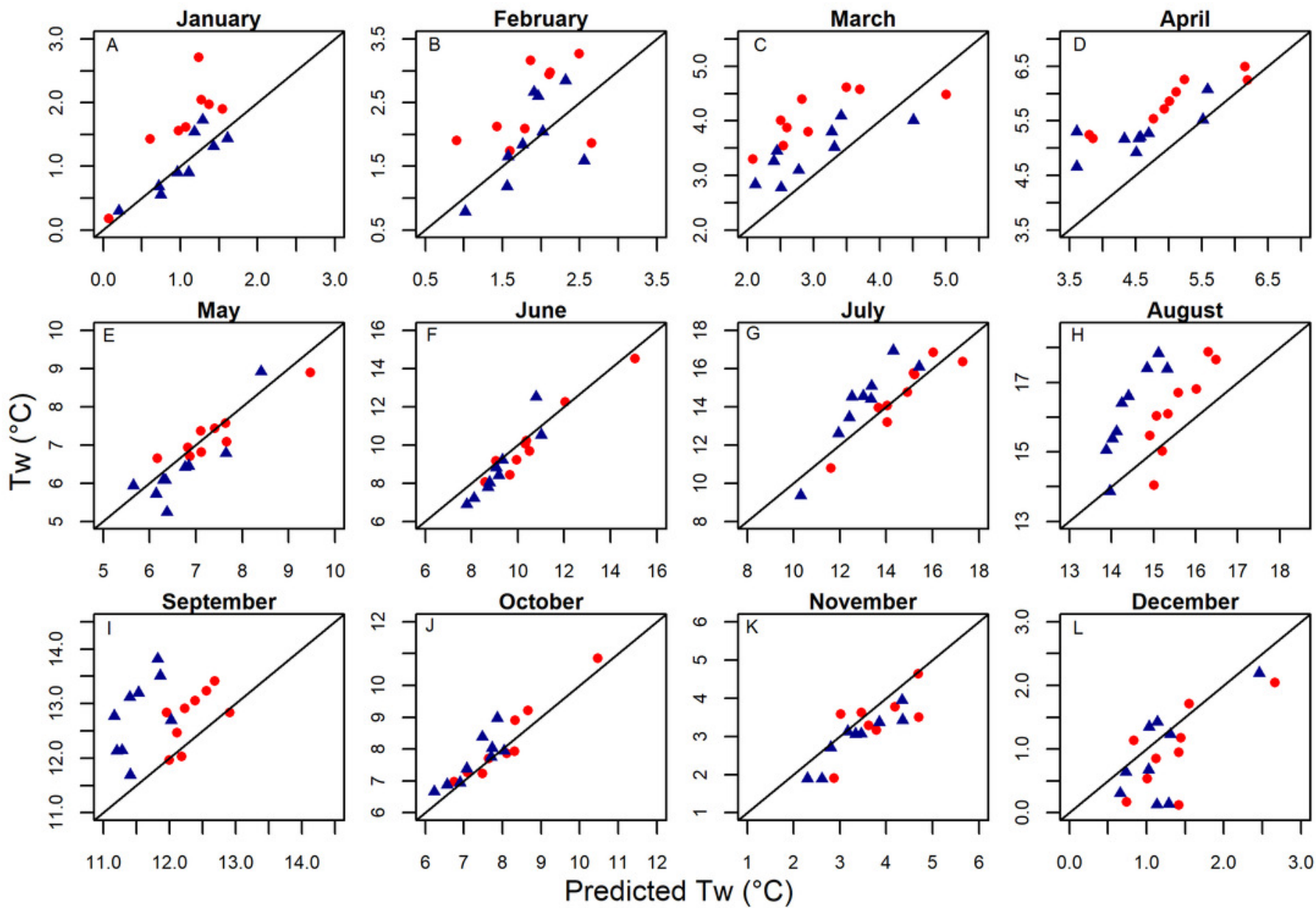
Figure 7

Example of accuracy and precision for average sites

Measured stream temperature, predicted values from selected GAM models, and residual error for the entire time series of single sites selected from the Wenatchee River training dataset (A, Upper Nason Creek) and testing dataset (B, Site \#220, White River). These sites were chosen for display due to having near median values of RMSE out of all sites in the respective datasets and largely continuous timeseries. Horizonal dashed lines presented at -2 and $2{ }^{\circ} \mathrm{C}$ to provide guidance on size of residuals.

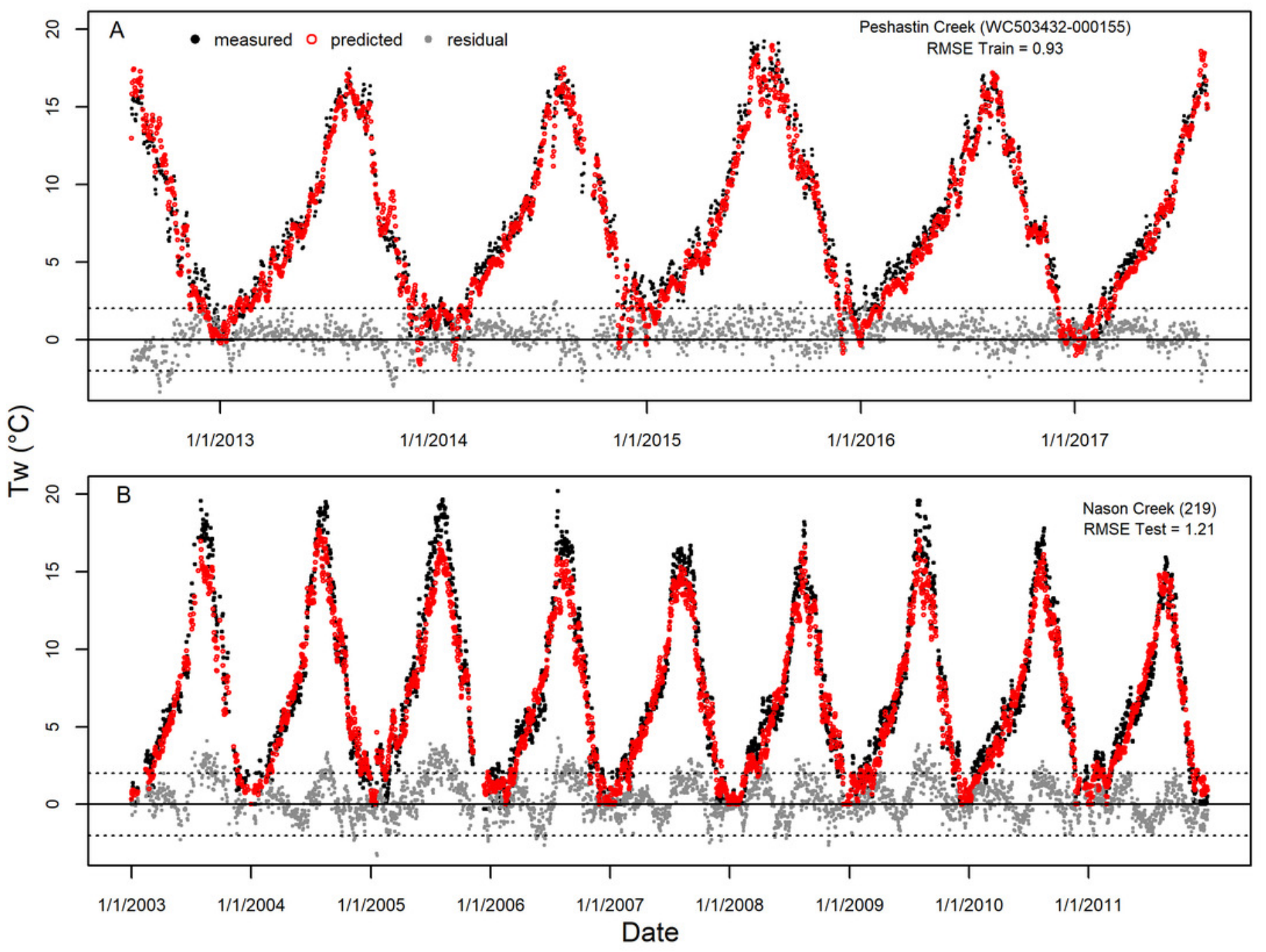




\section{Table $\mathbf{1}$ (on next page)}

\section{Dataset characteristics table}

Characteristics of model fitting and validation datasets shown for entire datasets and by month. The average temporal representation of sites varied across rivers and datasets. Effective coverage is the average percent of days with logger coverage for all sites within the respective time series (data days/[sites*years*365]). Data days by month is from all sites across all years. While data in fitting datasets were relatively evenly distributed across the year, data in validation datasets disproportionately cover summer months, particularly in the M.F. John Day and the Tucannon. 
1

\begin{tabular}{|c|c|c|c|c|c|c|c|c|c|}
\hline \multirow{2}{*}{\multicolumn{2}{|c|}{ Basin }} & \multicolumn{4}{|c|}{ Training datasets } & \multicolumn{4}{|c|}{ Testing datasets } \\
\hline & & Wenatchee & Chiwawa & M.F.J.D. & Tucannon & Wenatchee & Chiwawa & M.F.J.D. & Tucannon \\
\hline \multicolumn{2}{|l|}{ year range } & 2012-2017 & $\begin{array}{l}2012- \\
2017\end{array}$ & $\begin{array}{l}2012- \\
2017\end{array}$ & $\begin{array}{l}2012- \\
2017\end{array}$ & $2003-2011$ & $\begin{array}{l}2003- \\
2011\end{array}$ & $\begin{array}{l}1997- \\
2011\end{array}$ & $\begin{array}{l}2001- \\
2011\end{array}$ \\
\hline \multicolumn{2}{|l|}{ sites } & 40 & 11 & 45 & 41 & 36 & 3 & 179 & 21 \\
\hline \multicolumn{2}{|c|}{ sites per year (avg.) } & 28 & 8 & 22 & 34 & 20 & 3 & 34 & 13 \\
\hline \multicolumn{2}{|c|}{ effective coverage (\%) } & $52 \%$ & $56 \%$ & $33 \%$ & $67 \%$ & $42 \%$ & $63 \%$ & $16 \%$ & $55 \%$ \\
\hline \multicolumn{2}{|l|}{ data days } & 45,629 & 13,479 & 32,407 & 59,953 & 32,929 & 4,171 & 63,561 & 25,072 \\
\hline \multicolumn{2}{|c|}{ data days per year (avg.) } & 7,605 & 2,247 & 5,401 & 9,992 & 3,659 & 463 & 4,889 & 2,279 \\
\hline \multirow[t]{12}{*}{$\begin{array}{l}\text { data days by } \\
\text { month }\end{array}$} & Jan. & 4,051 & 1,209 & 2,493 & 5,052 & 1,862 & 232 & 434 & 514 \\
\hline & Feb. & 3,585 & 1,080 & 2,237 & 4,609 & 1,686 & 202 & 392 & 477 \\
\hline & Mar. & 4,115 & 1,209 & 2,506 & 5,028 & 1,972 & 235 & 365 & 527 \\
\hline & Apr. & 4,031 & 1,170 & 2,473 & 4,803 & 1,978 & 237 & 713 & 531 \\
\hline & May & 4,158 & 1,219 & 2,587 & 4,962 & 2,103 & 238 & 2,325 & 2,886 \\
\hline & Jun. & 3,988 & 1,135 & 2,777 & 4,757 & 2,294 & 242 & 8,115 & 3,590 \\
\hline & Jul. & 3,640 & 1,109 & 3,170 & 4,997 & 3,779 & 513 & 14,367 & 4,128 \\
\hline & Aug. & 3,747 & 1,176 & 3,369 & 5,517 & 5,544 & 806 & 15,078 & 4,278 \\
\hline & Sep. & 3,214 & 937 & 3,021 & 5,376 & 4,928 & 729 & 13,364 & 3,973 \\
\hline & Oct. & 3,866 & 1,100 & 2,907 & 5,361 & 3,020 & 349 & 5,897 & 3,250 \\
\hline & Nov. & 3,575 & 1,050 & 2,412 & 4,681 & 1,901 & 190 & 1,986 & 462 \\
\hline & Dec. & 3,659 & 1,085 & 2,455 & 4,810 & 1,862 & 198 & 525 & 456 \\
\hline
\end{tabular}

2 


\section{Table 2 (on next page)}

Table showing the variables considered for stream temperature models

Temporal (A) and spatial (B) variables considered as covariates in model selection with description of variable calculation, spatial and temporal characteristics, and rationale for inclusion. 


\begin{tabular}{|c|c|c|c|c|}
\hline Variable & Description & Spatial & Temporal & Rationale \\
\hline \multicolumn{5}{|c|}{ A. Temporal Variables } \\
\hline$D$ & Day of year (days) & NA & $\begin{array}{l}1 \text { day } \\
\text { means }\end{array}$ & $\begin{array}{l}\text { Accounts for seasonal changes in length of days } \\
\text { and solar angle }\end{array}$ \\
\hline$T 3_{a}$ & $\begin{array}{l}\text { Average air temperature from } 3 \text { day period } \\
\text { before predicted day }\left({ }^{\circ} \mathrm{C}\right)\end{array}$ & $\begin{array}{l}\text { From one point at } \\
\text { headwaters }\end{array}$ & $\begin{array}{l}5 \text { day } \\
\text { means }\end{array}$ & $\begin{array}{l}\text { The influence of air temperature on stream } \\
\text { temperature accumulates over time }\end{array}$ \\
\hline$T 5_{a}$ & $\begin{array}{l}\text { Average air temperature from } 5 \text { day period } \\
\text { before predicted day }\left({ }^{\circ} \mathrm{C}\right)\end{array}$ & $\begin{array}{l}\text { From one point at } \\
\text { headwaters }\end{array}$ & $\begin{array}{l}3 \text { day } \\
\text { means }\end{array}$ & $\begin{array}{l}\text { The influence of air temperature on stream } \\
\text { temperature accumulates over time }\end{array}$ \\
\hline$T \Delta_{a}$ & $\begin{array}{l}\text { Difference between utilized averaged } \\
\text { temperature variable }\left(\mathrm{T} 3_{a} / \mathrm{T} 5_{a}\right) \text { and mean } \\
\text { temperature the day of predictions }\left({ }^{\circ} \mathrm{C}\right)\end{array}$ & $\begin{array}{l}\text { From one point at } \\
\text { headwaters }\end{array}$ & $\begin{array}{l}1 \text { day } \\
\text { means }\end{array}$ & Air temperature effects temperature in real time \\
\hline$S$ & Snowpack depth & $\begin{array}{l}\text { From one point at } \\
\text { headwaters }\end{array}$ & $\begin{array}{l}1 \text { day } \\
\text { means }\end{array}$ & $\begin{array}{l}\text { More snowpack contributes colder water to } \\
\text { streamflow }\end{array}$ \\
\hline$S A 1$ & April 1st snowpack depth (cm) & $\begin{array}{l}\text { From one point at } \\
\text { headwaters }\end{array}$ & $\begin{array}{l}1 \text { day } \\
\text { means }\end{array}$ & $\begin{array}{l}\text { Magnitude of late snowpack has prolonged } \\
\text { effect on stream temperature into the summer } \\
\text { (delayed discharge, riparian growth) }\end{array}$ \\
\hline$F$ & Flow at USGS gage $(\mathrm{m} 3 / \mathrm{s})$ & From one point near mouth & $\begin{array}{l}1 \text { day } \\
\text { means }\end{array}$ & $\begin{array}{l}\text { Higher discharge creates more insulation } \\
\text { against atmospheric influences. Seasonally } \\
\text { different relationship (cooling in summer, } \\
\text { warming in winter) }\end{array}$ \\
\hline \multicolumn{5}{|c|}{ B. Spatial Variables } \\
\hline$E$ & Average elevation of catchment area (m) & $\begin{array}{l}\text { Summarized by catchment } \\
\text { area of the stream reach }\end{array}$ & NA & $\begin{array}{l}\text { Catchments with higher terrain will have cooler } \\
\text { streams even if the site is at a lower elevation. }\end{array}$ \\
\hline$E \Delta$ & $\begin{array}{l}\text { Difference between Elevation (catch) and } \\
\text { the site specific elevation }(\mathrm{m})\end{array}$ & $\begin{array}{l}\text { Summarized by catchment } \\
\text { area of the stream reach }\end{array}$ & NA & $\begin{array}{l}\text { Higher elevation sites experience cooler air } \\
\text { temperatures and are closer to cooler } \\
\text { headwaters }\end{array}$ \\
\hline$A$ & Catchment area of site $(\mathrm{km} 2)$ & $\begin{array}{l}\text { Summarized by catchment } \\
\text { area of the stream reach }\end{array}$ & NA & $\begin{array}{l}\text { Sites further from headwaters have more time to } \\
\text { be effected by atmospheric temperatures. }\end{array}$ \\
\hline$B F I$ & $\begin{array}{l}\text { Base flow index (mean low flow } \div \text { mean } \\
\text { annual discharge) }\end{array}$ & $\begin{array}{l}\text { Summarized by catchment } \\
\text { area of the stream reach }\end{array}$ & NA & $\begin{array}{l}\text { Areas with higher groundwater influence will } \\
\text { have mitigated stream temperatures (lower } \\
\text { highs and higher lows). Developed by Wolock } \\
\text { (2003). }\end{array}$ \\
\hline$L$ & Percentage of catchment covered by lakes & $\begin{array}{l}\text { Summarized by catchment } \\
\text { area of the stream reach }\end{array}$ & NA & $\begin{array}{l}\text { Lakes slow down water leading to increased } \\
\text { atmospheric warming. }\end{array}$ \\
\hline$S L$ & Slope of stream reach & $\begin{array}{l}\text { Summarized by stream } \\
\text { reach }\end{array}$ & NA & $\begin{array}{l}\text { Steeper streams move cooler water downstream } \\
\text { faster. }\end{array}$ \\
\hline$F C / F R$ & $\begin{array}{l}\text { Forest cover percentage of reach } \\
\text { contributing area }(F R) \text { or catchment }(F C)\end{array}$ & $\begin{array}{l}\text { Summarized by reach } \\
\text { contributing area and } \\
\text { catchment area of the } \\
\text { stream reach }\end{array}$ & NA & $\begin{array}{l}\text { Forested areas provide more stream shading and } \\
\text { retention of moisture/snowpack }\end{array}$ \\
\hline
\end{tabular}




\section{Table 3 (on next page)}

Table showing the variables and interactions utilized for each model

Model selection table showing retained covariate (Cov.) and interactions (Int.) in GAM and linear models for the Wenatchee, Chiwawa, M.F. John Day and Tucannon watersheds (A) and fitting and model prediction statistics for selected models (B). Retained variables are in represented by grey boxes. GAM and Linear models generally retained analogous covariates, however differences are shown by letters, with $G$ representing variables only in GAM models and L only in linear models. Glaciers are not present in the M.F. John Day and the Tucannon watersheds and thus were not considered as a covariate. Knots were limited in model GAM model fitting to reduce risk of overfitting. Selected model AIC values, as well as model fit and testing dataset prediction metrics, are also provided including the root mean squared error (RMSE) and Nash-Stutclife Coeficients (NSC) for selected GAM and linear models. Statistics are shown for the model fit (Train.), cross validation (C.V.), and testing dataset predictions (Test.). 


\begin{tabular}{|c|c|c|c|c|c|c|c|c|c|c|c|c|c|c|c|c|c|c|}
\hline \multirow{3}{*}{ Cov. } & \multirow{3}{*}{ Int. } & \multirow{3}{*}{$\mathrm{K}$} & \multicolumn{4}{|c|}{ Wenatchee } & \multicolumn{4}{|c|}{ Chiwawa } & \multicolumn{4}{|c|}{ M.F.J.D } & \multicolumn{4}{|c|}{ Tucannon } \\
\hline & & & & & & & & & & & & & $\mathrm{Fr}$ & & & & & all \\
\hline & & & GAM & Lin. & GAM & Lin. & GAM & Lin. & GAM & Lin. & GAM & Lin. & GAM & Lin. & GAM & Lin. & GAM & Lin. \\
\hline
\end{tabular}

A. Variable Selection

\begin{tabular}{|c|c|}
\hline \multicolumn{2}{|c|}{ Climate } \\
\hline$D$ & $T 3 / 5$ \\
\hline T3a & \\
\hline$T 5 a$ & \\
\hline$T \delta a$ & \\
\hline$F$ & $T 3 / 5$ \\
\hline$S$ & $T 3 / 5$ \\
\hline SAI & $D$ \\
\hline
\end{tabular}
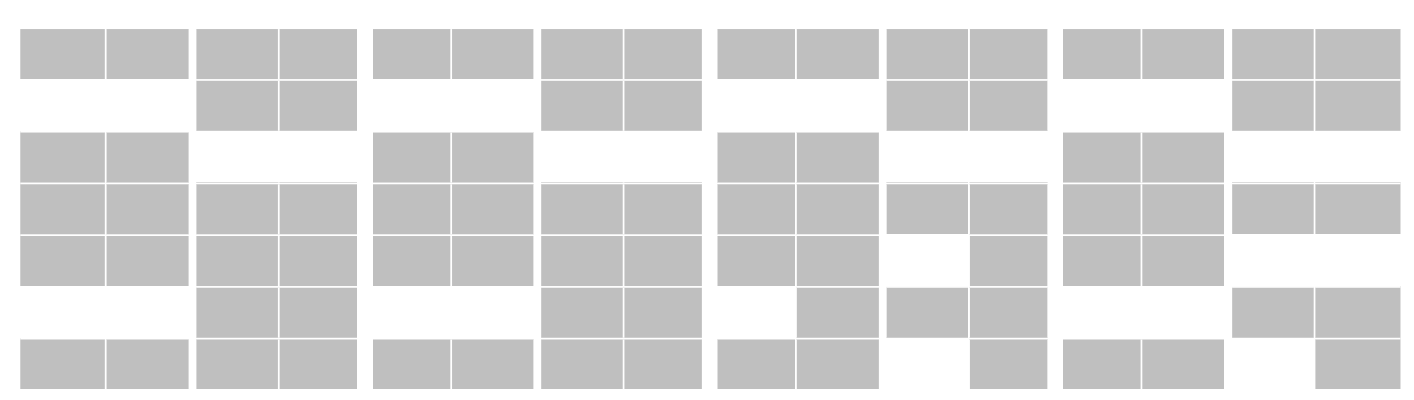

Spatial

$$
\text { A } \quad \text { E } 3
$$
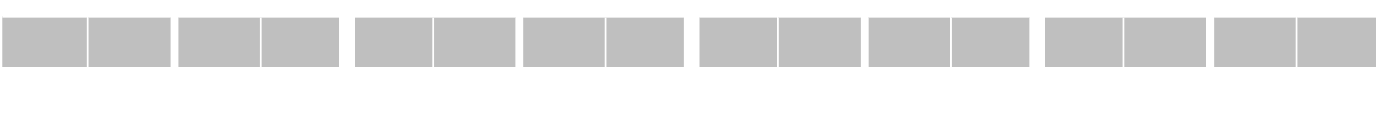

\begin{tabular}{lll}
\multicolumn{3}{l}{ Spatial } \\
$A$ & Climate \\
$A$ & $T 3 / 5$ & 3 \\
$E$ & $F$ & 3 \\
$E$ & $D$ & 3 \\
$E 4$ & $T 3 / 5$ & 3 \\
$B F I$ & $T 3 / 5$ & 3 \\
$L$ & $D$ & 3 \\
$F C$ & $T 3 / 5$ & 3 \\
$F R$ & $T 3 / 5$ & 3 \\
$S L$ & $T 3 / 5$ & 3 \\
$G$ & $T 3 / 5$ & 3
\end{tabular}
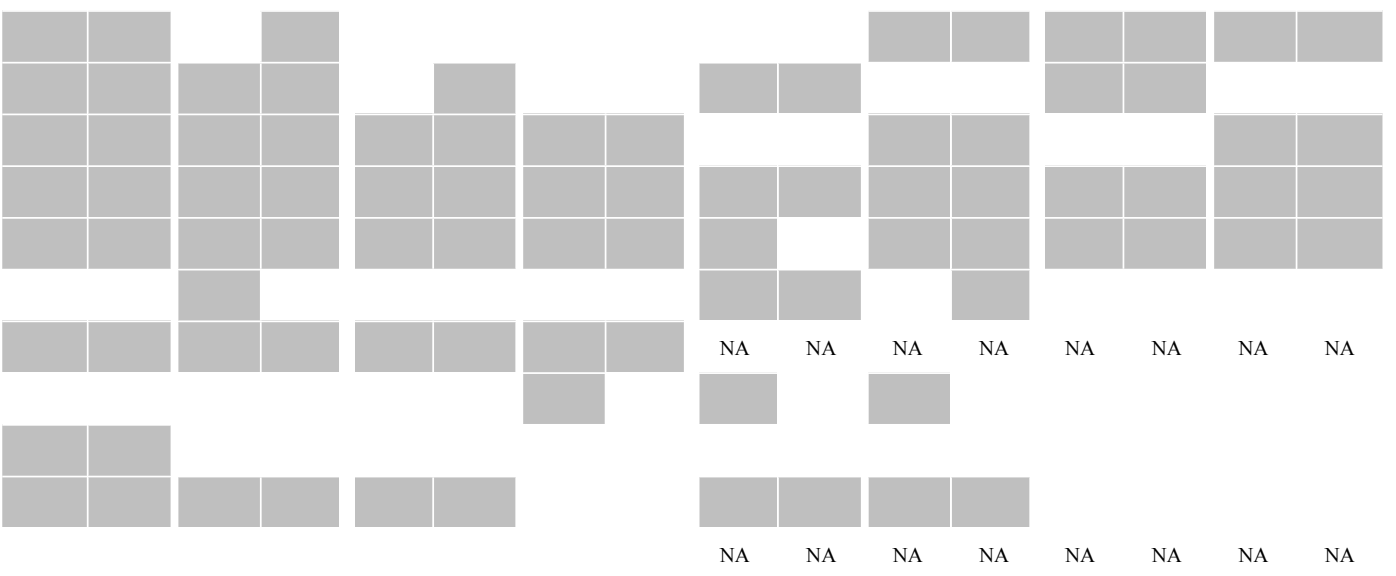

B. Selected Model Statistics

\begin{tabular}{|c|c|c|c|c|c|c|c|c|c|c|c|c|c|c|c|c|}
\hline Terms & 14 & 27 & 12 & 24 & 12 & 22 & 11 & 22 & 13 & 21 & 12 & 19 & 11 & 15 & 8 & 13 \\
\hline$\triangle A I C$ & 0 & 1426 & 0 & 954 & 0 & 334 & 0 & 297 & 0 & 4256 & 0 & 884 & 0 & 4391 & 0 & 3337 \\
\hline RMSE Train. & 0.95 & 1.12 & 0.97 & 1.15 & 0.62 & 0.63 & 0.78 & 0.81 & 1.11 & 1.42 & 1.27 & 1.46 & 0.85 & 0.91 & 1.08 & 1.15 \\
\hline RMSE C.V. & 1.09 & 1.06 & 1.35 & 1.35 & 0.67 & 1.17 & 0.84 & 1.10 & 1.30 & 1.44 & 1.54 & 1.53 & 0.87 & 0.92 & 1.09 & 1.16 \\
\hline RMSE Test. & 1.18 & 1.30 & 1.32 & 1.44 & 0.70 & 0.78 & 0.93 & 0.89 & 1.52 & 1.81 & 1.56 & 1.80 & 0.88 & 1.01 & 1.00 & 1.01 \\
\hline NSC Train. & 0.96 & 0.95 & 0.95 & 0.95 & 0.98 & 0.97 & 0.95 & 0.96 & 0.96 & 0.95 & 0.94 & 0.94 & 0.97 & 0.96 & 0.95 & 0.95 \\
\hline NSC Test. & 0.94 & 0.93 & 0.93 & 0.91 & 0.98 & 0.97 & 0.95 & 0.96 & 0.90 & 0.85 & 0.89 & 0.85 & 0.97 & 0.96 & 0.95 & 0.95 \\
\hline
\end{tabular}

1 


\section{Table 4 (on next page)}

Model prediction statistics table

Testing dataset prediction error (RMSE) and goodness of fit measures (NSC) for selected GAM and linear models shown for aggregated monthly predictions by month for the Wenatchee, Chiwawa, M.F. John Day and Tucannon watersheds respectively. 
1

\begin{tabular}{|c|c|c|c|c|c|c|c|c|c|c|c|c|c|c|c|c|}
\hline \multirow[b]{3}{*}{ Month } & \multicolumn{4}{|c|}{ Wenatchee } & \multicolumn{4}{|c|}{ Chiwawa } & \multicolumn{4}{|c|}{ M.F.J.D. } & \multicolumn{4}{|c|}{ Tucannon } \\
\hline & \multicolumn{2}{|c|}{ RMSE Test. } & \multicolumn{2}{|c|}{$\mathrm{NSC}$} & \multicolumn{2}{|c|}{ RMSE Test. } & \multicolumn{2}{|c|}{ NSC } & \multicolumn{2}{|c|}{ RMSE Test. } & \multicolumn{2}{|c|}{ NSC } & \multicolumn{2}{|c|}{ RMSE Test. } & \multicolumn{2}{|c|}{ NSC } \\
\hline & GAM & Lin & GAM & Lin & GAM & Lin & GAM & Lin & GAM & Lin & GAM & Lin & GAM & Lin & GAM & Lin \\
\hline January & 0.81 & 1.01 & 0.35 & 0.00 & 0.15 & 0.21 & 0.75 & 0.52 & 0.58 & 0.71 & -0.09 & -0.66 & 0.51 & 0.69 & 0.63 & 0.32 \\
\hline February & 0.58 & 0.69 & 0.50 & 0.29 & 0.35 & 0.34 & 0.42 & 0.47 & 0.58 & 0.90 & -0.11 & -1.65 & 0.46 & 0.51 & 0.78 & 0.72 \\
\hline April & 0.77 & 0.80 & 0.66 & 0.64 & 0.45 & 0.38 & 0.00 & 0.29 & 1.19 & 1.31 & 0.50 & 0.40 & 0.90 & 0.89 & 0.80 & 0.80 \\
\hline May & 0.89 & 0.94 & 0.76 & 0.73 & 0.25 & 0.28 & 0.94 & 0.93 & 1.31 & 1.46 & 0.61 & 0.52 & 0.75 & 0.74 & 0.91 & 0.92 \\
\hline June & 1.16 & 1.20 & 0.80 & 0.78 & 0.58 & 0.72 & 0.94 & 0.90 & 1.28 & 1.56 & 0.78 & 0.68 & 0.60 & 0.64 & 0.96 & 0.96 \\
\hline July & 1.28 & 1.46 & 0.78 & 0.71 & 0.70 & 0.91 & 0.90 & 0.83 & 1.36 & 1.73 & 0.74 & 0.57 & 0.68 & 0.70 & 0.96 & 0.96 \\
\hline August & 1.40 & 1.47 & 0.69 & 0.66 & 0.87 & 0.78 & 0.74 & 0.79 & 1.38 & 1.71 & 0.64 & 0.44 & 0.73 & 0.72 & 0.95 & 0.96 \\
\hline September & 0.90 & 1.00 & 0.77 & 0.72 & 0.46 & 0.41 & 0.76 & 0.81 & 1.09 & 1.45 & 0.70 & 0.47 & 0.60 & 0.58 & 0.95 & 0.96 \\
\hline October & 0.82 & 0.92 & 0.77 & 0.71 & 0.44 & 0.43 & 0.86 & 0.87 & 1.15 & 1.31 & 0.63 & 0.52 & 0.77 & 0.78 & 0.88 & 0.87 \\
\hline November & 0.99 & 1.37 & 0.78 & 0.57 & 0.87 & 0.70 & -6.09 & -3.52 & 1.28 & 1.46 & 0.08 & -0.19 & 0.71 & 0.95 & 0.85 & 0.74 \\
\hline December & 1.00 & 1.19 & 0.59 & 0.42 & 1.02 & 0.38 & -8.62 & -0.32 & 1.50 & 1.59 & -3.02 & -3.56 & 0.91 & 1.13 & -0.33 & -1.03 \\
\hline Year & 1.03 & 1.15 & 0.95 & 0.94 & 0.62 & 0.60 & 0.98 & 0.98 & 1.26 & 1.56 & 0.92 & 0.88 & 0.70 & 0.72 & 0.98 & 0.98 \\
\hline
\end{tabular}

2 


\section{Table 5 (on next page)}

Table showing the sensitivity analysis results of decaying model prediction error with fewer sites and years respectively

Table showing mean root mean squared error for testing dataset predictions (RMSE test.) in model sensitivity analyses varying the number of years (A) and number of sites (B) utilized in the training datasets independently. RMSE Test. was calculated from 100 iterations of randomly chosen sites/years out of all available for each sensitivity scenario (or all combinations if there were fewer than 100). The percent increase in prediction error from models fit with all data are shown in parenthesis. Model selection was not repeated for each scenario, and thus the same model formulas for each watershed was used for all scenario iterations. Note, sites have varying temporal coverage out of the entire time series of the fitting dataset and thus the removal of different sites/years represents different quantities of data. Percentage given for each watershed represents the average effective coverage percentage for each site in the fitting datasets (data days/[sites*years*365]). 


\begin{tabular}{|c|c|c|c|c|c|c|c|c|}
\hline & \multicolumn{2}{|c|}{ Wenatchee $(52 \%)$} & \multicolumn{2}{|c|}{ Chiwawa (56\%) } & \multicolumn{2}{|c|}{ M.F. John Day (33\%) } & \multicolumn{2}{|c|}{ Tucannon $(67 \%)$} \\
\hline & GAM & Linear & GAM & Linear & GAM & Linear & GAM & Linear \\
\hline \multicolumn{9}{|c|}{ A. Years } \\
\hline 6 (All) & 1.26 & 1.37 & 0.85 & 0.85 & 1.55 & 1.80 & 0.95 & 0.98 \\
\hline 5 & $1.28(2 \%)$ & $1.38(1 \%)$ & $0.88(3 \%)$ & $0.85(1 \%)$ & $1.68(8 \%)$ & $1.88(4 \%)$ & $0.96(1 \%)$ & $0.99(1 \%)$ \\
\hline 4 & $2.13(70 \%)$ & $1.40(2 \%)$ & $1.33(55 \%)$ & $0.88(4 \%)$ & $1.94(10 \%)$ & $1.97(10 \%)$ & $0.99(4 \%)$ & $1.01(4 \%)$ \\
\hline 3 & $2.53(101 \%)$ & $1.68(22 \%)$ & $2.71(217 \%)$ & $1.03(22 \%)$ & $2.33(51 \%)$ & $2.07(15 \%)$ & $1.23(30 \%)$ & $1.09(11 \%)$ \\
\hline & & & & B. Sites & & & & \\
\hline All & 1.26 & 1.37 & & & 1.55 & 1.80 & 0.95 & 0.98 \\
\hline 35 & $1.32(5 \%)$ & $1.39(1 \%)$ & & & $1.68(9 \%)$ & $1.83(2 \%)$ & $0.95(0 \%)$ & $0.98(0 \%)$ \\
\hline 30 & $1.42(14 \%)$ & $1.41(3 \%)$ & & & $1.79(16 \%)$ & $1.86(3 \%)$ & $0.95(0 \%)$ & $0.98(0 \%)$ \\
\hline 25 & $1.63(30 \%)$ & $1.45(6 \%)$ & & & $1.94(25 \%)$ & $1.88(5 \%)$ & $0.96(2 \%)$ & $1.00(2 \%)$ \\
\hline 20 & $1.88(50 \%)$ & $1.54(12 \%)$ & & & $2.48(60 \%)$ & $1.97(10 \%)$ & $0.97(2 \%)$ & $1.01(3 \%)$ \\
\hline 15 & $2.58(106 \%)$ & $1.72(25 \%)$ & & & $3.14(103 \%)$ & $2.11(17 \%)$ & $1.06(12 \%)$ & $1.07(9 \%)$ \\
\hline 10 & $6.30(401 \%)$ & $2.81(104 \%)$ & & & $9.47(511 \%)$ & $3.07(70 \%)$ & $1.33(40 \%)$ & $1.26(30 \%)$ \\
\hline
\end{tabular}

1 